\title{
ESTUDIO DE LOS CORALES LITHOSTROTIÓNIDOS DEL VISEENSE (MISISIPIENSE) DE LA UNIDAD DE LA SIERRA DEL CASTILLO (CÓRDOBA, ESPAÑA)
}

\author{
Sergio RODRÍGUEZ', José Miguel HERNANDO y \\ Lucía RODRÍGUEZ-CURT
}

\author{
' Departamento y U.E.I de Paleontología, Facultad de Ciencias Geológicas e Instituto de \\ Geología Económica. U.C.M. y CSIC, 28040) Madrid. España
}

Rodríguez, S., Hernando, J.M. y Rodríguez-Curt, L. 2002. Estudio de los corales lithostrotiónidos del Viseense (Misisipiense) de la Unidad de la Sierra del Castillo (Córdoba, España). 「Study on the Viséan (Mississippian) lithostrotionid corals from the Sierra del Castillo Unit (Córdoba, Spain).l Revista Española de Paleontología. 17(1), 13-36. ISSN 0213-6937.

\begin{abstract}
ABSTRAC'T
Viséan rugose corals belonging to the family Lithostrotionidae are studied in this paper. Corals were recorded at seven localities from three different areas (Sierra del Castillo. Sierra de la Estrella and Antolín; Córdoba) at the Guadiato Area (Ossa Morena). Ten species belonging to two genera have been identified and described in detail: Lithostrotion vorticale (Parkinson, 1808), Lithostrotion araneum (McCoy, 1844), Siphonodendron junceum (Fleming, 1828), Siphonodendron pauciradiale (McCoy, 1844), Siphonodendron irregulare (Phillips, 1836), Siphonodendron intermedium Poty, 1981, Siphonodendron martini (Milne-Edwards and Haime, 1851), Siphonodendron sociale (Phillips, 1836), Siphonodendron scaleberense Nudds and Somerville, 1987 and Siphonodendron aff. martini. The latter represents an ecological variety of the nominal species adapted to reefal environments. Microstructural features of all species are described in detail. Siphonodendron scaleberense is recorded for the first time out fiom British Islands.
\end{abstract}

Keywords: Systematics, Lithostrotionidae, Rugosa, Sierra del Castillo Unit, Guadiato Area, OssaMorena, Viséan, Carboniferous.

\section{RESUMEN}

Los corales rugosos con disepimentos son frecuentes en la Unidad de la Sierra del Castillo, que comprende materiales predominantemente carbonatados del Viseense del Área del Guadiato (Ossa-Morena). Se han estudiado las asociaciones de la Sierra del Castillo, de la Sierra de la Estrella (ambas en el término de Espiel, Córdoba) y las de la zona de Antolín (en el término de Peñarroya, Córdoba) en las que se han identificado 10 especies pertenecientes a 2 géneros. El estudio sistemático de estos corales ha permitido hacer importantes precisiones, entre las que destacan:

- Descripción precisa de la microestructura de todas las especies

- Descripción de una forma del género Siphonodendron próxima a S. martini del que probablemente representa una variante, condicionada por factores ambientales.

Palabras clave: Sistemática, Lithostrotionidae, Rugosa, Unidad de la Sierra del Castillo, Área del Guadiato, Ossa-Morena, Viseense, Carbonífero.

\section{INTRODUCCIÓN}

Este trabajo tiene como objetivo dar a conocer las asociaciones de corales lithostrotiónidos de la Unidad de la Sierra del Castillo (Córdoba, España). Esta Unidad fue definida por Cózar y Rodríguez (1999) y se compone de varias escamas constituidas básicamente por rocas carbonáticas marinas de edad Viseense Superior. Las zonas donde se localizan los corales estudiados (Sierra del Castillo, Sierra de la Estrella y Antolín, Fig. 1) han sido descritas en profundidad por Cózar (1996, 1998), Cózar y Rodríguez (2000), Rodríguez-Martínez et al. (2000) y Rodríguez et al. (en prensa), por lo que no entraremos a describirlas en detalle en este trabajo. Casi 


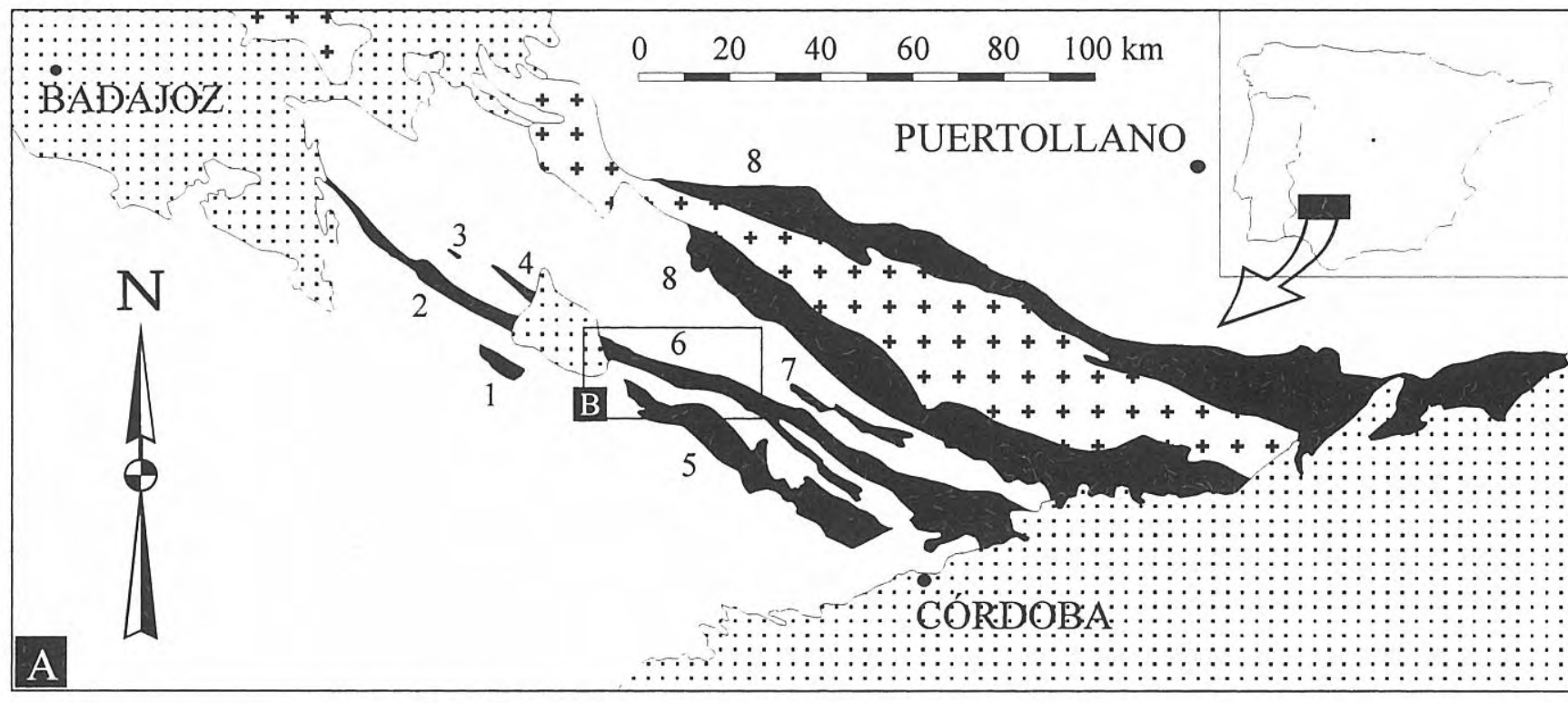

$\because::$ Postpaleozoico $\quad+\div$ Batolito de los Pedroches

Paleozoico no diferenciado

Áreas incluidas en la Cuenca carbonífera del Norte de Ossa-Morena:

1.- Berlanga, 2.- Matachel, 3.- El Casar, 4.- Campillo de Llerena, 5.- Benajarafe, 6.- Guadiato-Guadalmellato, 7.- Guadalbarbo, 8.- Pedroches.

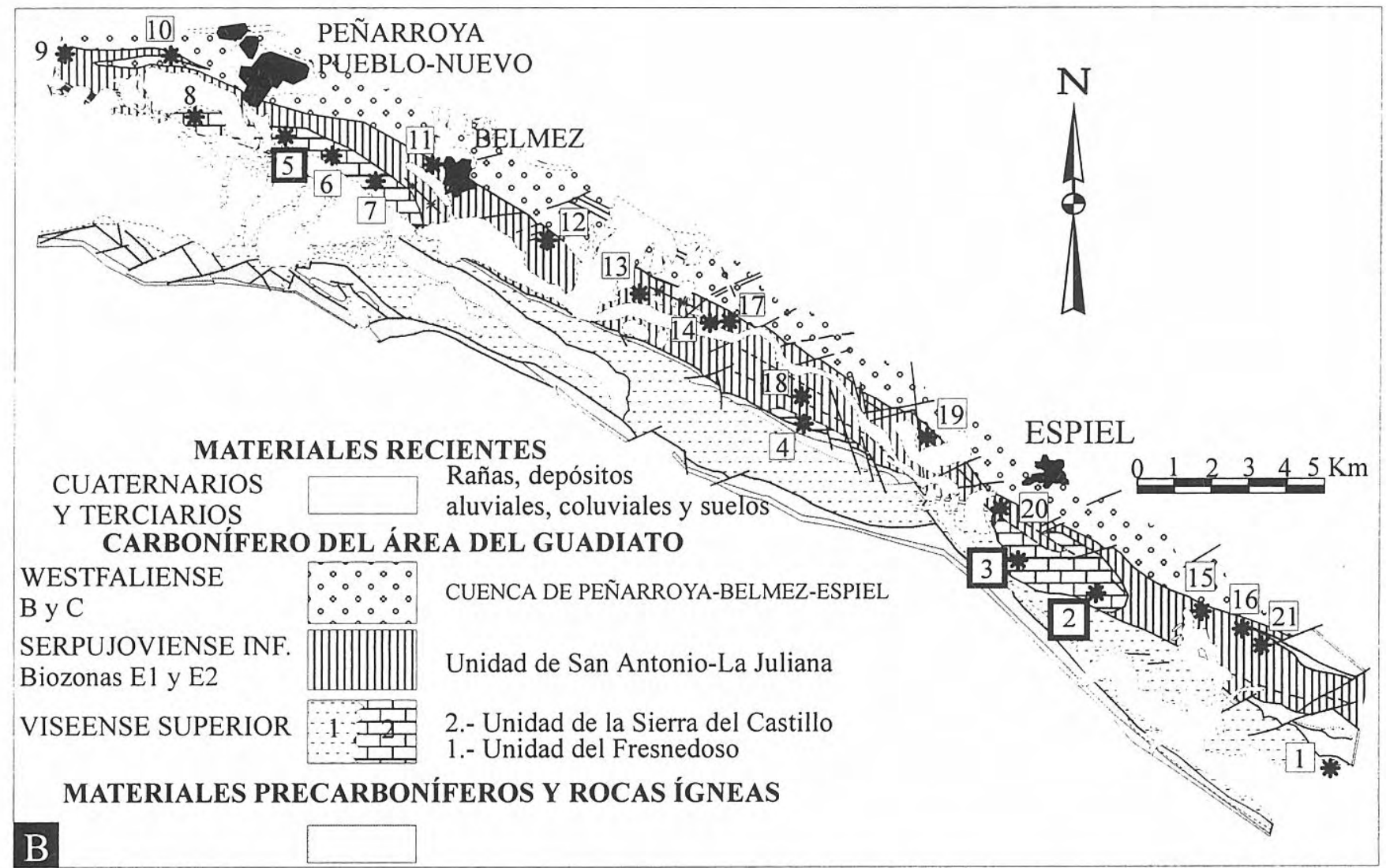

Figura 1. Localización de los afloramientos estudiados. A. Afloramientos de la cuenca carbonífera del norte de Ossa-Morena. B. Esquema geológico del área del Guadiato. Los afloramientos estudiados se numeran de 1 a 21 . Los corales descritos en este trabajo proceden de las localidades 2 (Sierra de la Estrella), 3 (Sierra del Castillo) y 5 (Antolín). Modificado de Cózar y Rodríguez (1999).

Location of the studied outcrops. A. Carboniferous outcrops in the North Ossa-Morena Zone. B. Geological sketch of the Guadiato Area. The studied outcrops are numbered from 1 to 21. Corals described in this paper come from localities 2 (Sierra de la Estrella), 3 (Sierra del Castillo) and 5 (Antolín). Modified from Cózar and Rodríguez (1999). 
toda la sucesión estratigráfica de las localidades estudiadas se engloba en el Viseense Superior (AsbienseBrigantiense). Sólo los niveles basales de la sección de la Cantera pueden representar el techo del Viseense Medio. El límite entre el Asbiense y el Brigantiense se sitúa en los tramos 7-8 de la sección de el Collado.

Los corales rugosos son frecuentes en todos los afloramientos de la Unidad de la Sierra del Castillo. Entre ellos, los más abundantes son los lithostrotiónidos, que en algunos niveles llegan a constituir porcentajes muy importantes de la roca, como sucede en los primeros tramos de la sección de El Collado y en los debris calcáreos de la sección de Antolín. En la Sierra del Castillo, los lithostrotiónidos son muy variados y presentan formas típicas que no pueden distinguirse de las existentes en otras áreas geográficas con abundantes corales rugosos viseenses, como Bélgica, Islas Británicas o el Norte de África. Sin embargo, las asociaciones de la Sierra de la Estrella presentan lithostrotiónidos menos frecuentes y con ciertas peculiaridades en su desarrollo que son achacables a condiciones ambientales cambiantes. En Antolín los lithostrotiónidos son tan abundantes como en la Sierra del Castillo, pero menos diversos y también con características morfológicas peculiares.

\section{BREVE DESCRIPCIÓN DE LOS AFLORAMIENTOS}

\section{SIERRA DEL CASTILLO}

La Sierra del Castillo se halla en la provincia de Córdoba a escasos kilómetros de la localidad de Espiel (Fig. 1). Está ubicada entre las hojas 880 (Espiel) y 901 (Villaviciosa de Córdoba) del mapa geológico de España (escala 1:50.000). Está constituida en su totalidad por materiales del Viseense que son predominantemente carbonáticos. Aunque hay una karstificación muy importante que oscurece la traza de las capas, los afloramientos se encuentran entre los mejores del valle del Guadiato. En esta zona se han levantado dos secciones estratigráficas, que conjuntamente cubren toda la sucesión aflorante.

\section{Sección de la Cantera de la Sierra del Castillo (CCS, Fig.} 2)

En esta sección afloran de forma excelente los niveles inferiores de la sucesión de la Sierra del Castillo. La sección original fue levantada en 1993 por M.E. Arribas Mocoroa,

Figura 2. Distribución de los lithostrotiónidos en la Sierra del Castillo. La columna inferior corresponde a la sección de la Cantera y la superior a la sección del Collado.

Distribution of lithostrotionid corals in the Sierra del Castillo. Lower column corresponds to the Cantera Section, upper column corresponds to the Collado Section.

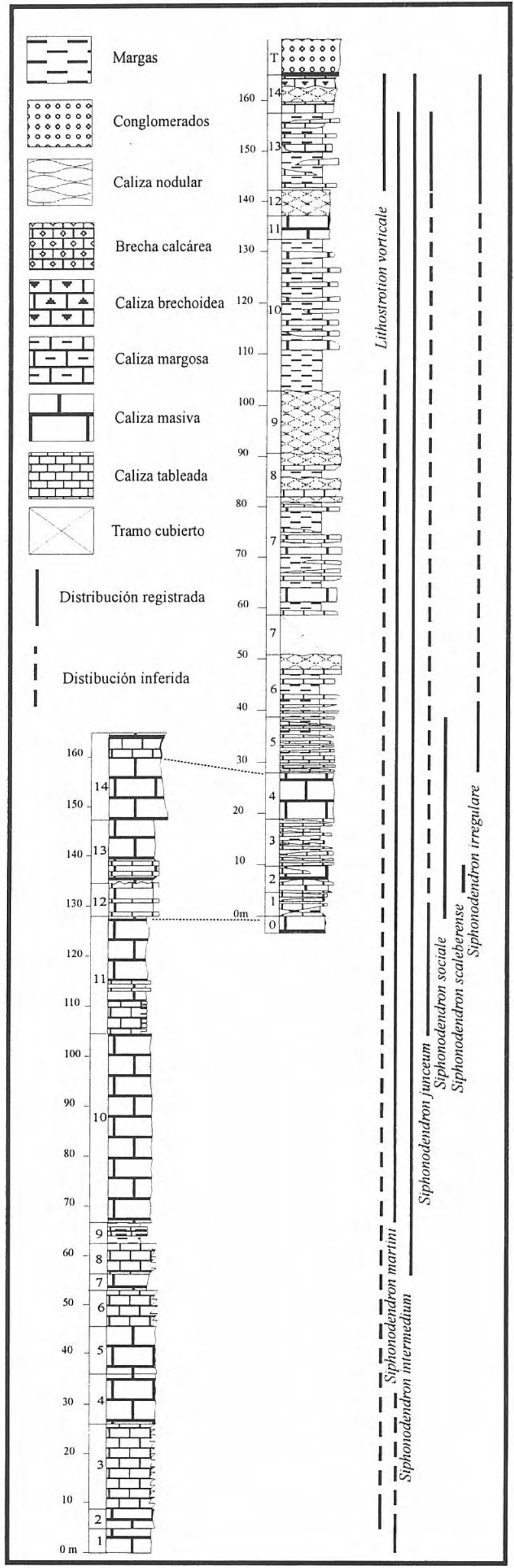




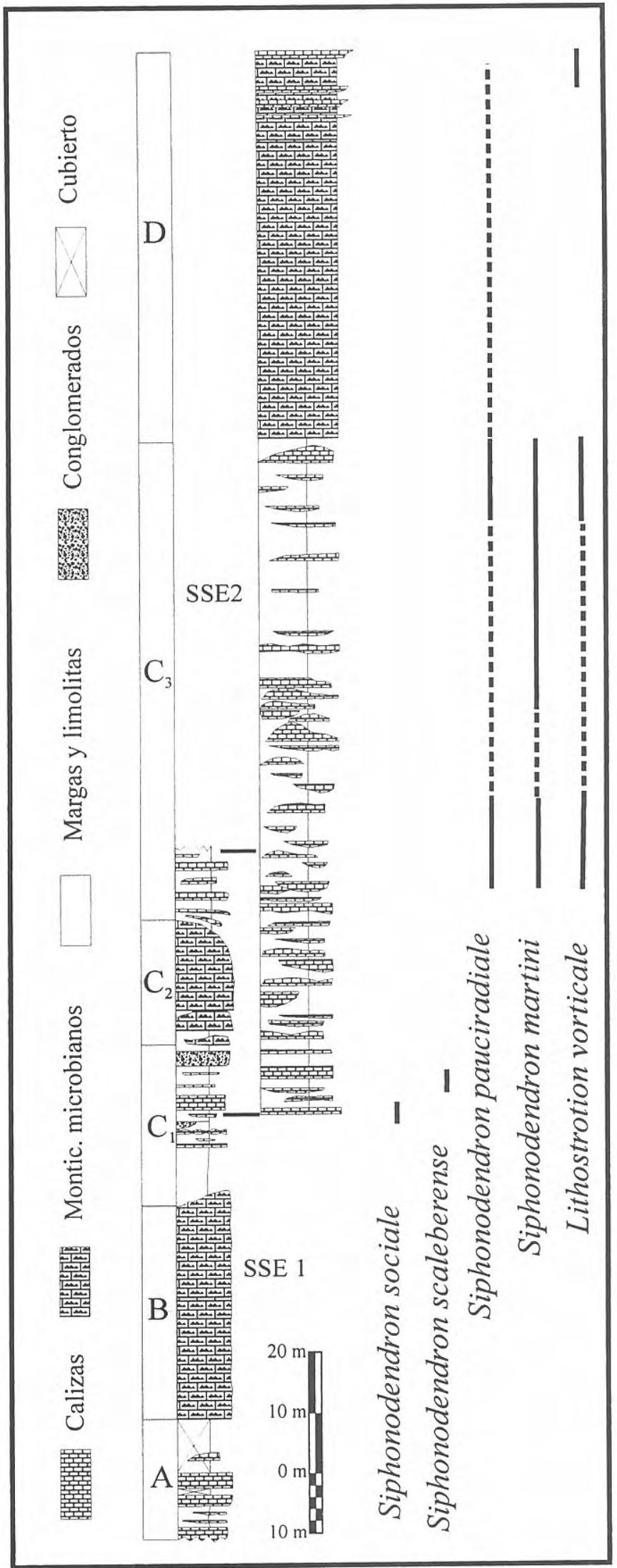

Figura 3. Distribución de los lithostrotiónidos en la Sierra de la Estrella. Modificado de Cózar et al. (en prensa).

Distribution of lithostrotionid corals in the Sierra del Castillo. Modified from Cózar et al. (in press).
E. Moreno-Eiris y P. Cózar., pero la intensa actividad que se lleva a cabo en la cantera ha provocado la destrucción total del afloramiento en donde se levantó. Sin embargo, la sucesión estratigráfica es todavía reconocible en los niveles de la cantera más altos topográficamente. Esta sección ya ha sido descrita por Moreno-Eiris et al. (1995), Cózar (1996), Rodríguez y Falces (1996), y fundamentalmente por Cózar (1994).

La sección está constituida básicamente por calizas; hay niveles bien estratificados, con bancos decimétricos, y niveles masivos que alcanzan varios metros de espesor. También se encuentran algunos niveles margosos intercalados, sobre todo en la parte superior de la sección. Los niveles inferiores tienen un escaso contenido en macrofósiles, que son frecuentes en los tramos superiores, especialmente los corales rugosos.

\section{Sección de EI Collado (COL, Fig. 2)}

Esta sección fue también levantada por M.E. ArribasMorocoa, E. Moreno-Eiris y P. Cózar, aunque revisiones posteriores realizadas por P. Cózar y S. Rodríguez han permitido modificar algunos aspectos de la sección original. Los primeros tramos (1-5) pueden correlacionarse en el terreno con los niveles superiores de la sección de la Cantera (12-14), situada un kilómetro al oeste de ésta, por lo que ambas secciones son complementarias. Como en la sección de la Cantera, aquí predominan las calizas, tanto bien estratificadas como nodulosas y masivas, pero hay frecuentes niveles margosos que afloran mal. Los corales son frecuentes en toda la sección, especialmente en los niveles inferiores, que llegan a presentar estratos constituidos casi exclusivamente por fragmentos de lithostrotiónidos. En los niveles superiores, aunque menos abundantes, los corales están frecuentemente enteros.

\section{SIERRA DE LA ESTRELLA}

La Sierra de la Estrella está situada al sureste de la Sierra del Castillo (Fig. 1). Pese a estar muy próximos, y separados tan solo por una falla, el bloque de la Sierra de la Estrella es muy distinto litológicamente al de la Sierra del Castillo. La Sierra de la Estrella presenta una alternancia de grandes masas de caliza bioconstruida y de sucesiones de calizas margosas y margas. También se encuentran algunos niveles siliciclásticos. La karstificación a la que están sometidas las calizas en esta zona es muy intensa, por lo que la exposición de los tramos masivos no es buena. Por ello, la sucesión total ha tenido que ser identificada por la combinación de varias secciones estratigráficas parciales que se han correlacionado por su disposición espacial en el terreno. La potencia total de la sucesión en esta área es de unos $110 \mathrm{~m}$. Se observan corales rugosos con y sin disepimentos en numerosos niveles, aunque los componentes más frecuentes son los crinoides. También se observan poríferos, braquiópodos, bivalvos y gasterópodos. Los niveles masivos corresponden a montículos microbianos y presentan más raramente corales. Las dos secciones, que combinadas permiten reconocer toda la sucesión estratigráfica en esta área, fueron levantadas originalmente por P. Cózar, y han sido revisadas y completadas por S. Rodríguez. 


\section{Sierra de la Estrella 1 (SSE1, Fig. 3)}

La base de esta sucesión está parcialmente cubierta por vegetación. Se caracteriza por una alternancia de capas de margas y margocalizas con calizas bioclásticas y microbianas. Los corales rugosos sin disepimentos son frecuentes en todos los tramos margosos y margocalizos, en tanto que los corales rugosos con disepimentos aparecen en algunos tramos de calizas bioclásticas. En el tramo 10 se localiza un nivel con pequeños biohermos constituidos por algas, corales rugosos y tabulados y poríferos. Estos corales están en posición de vida, pero en el resto de la sección los corales están generalmente removilizados.

\section{Sierra de la Estrella 2 (SSE2, Fig. 3)}

Los niveles basales de esta sección pueden correlacionarse geométricamente en el terreno con los del techo de SSE1. La mayor parte de la columna estratigráfica consiste en una alternacia de niveles margocalizos y calizas bioclásticas. Los niveles margocalizos afloran muy mal y hay poco control de su contenido paleontológico. Los niveles bioclásticos contienen esporádicamente corales rugosos. Los niveles superiores de la columna (tramo 6), constituidos por calizas masivas organógenas, corresponden a un montículo microbiano semejante al existente en los niveles inferiores de la Estrella 1.

\section{ANTOLÍN}

Los afloramientos de Antolín se sitúan al sur de Peñarroya-Pueblonuevo (Fig. 1) y al noroeste de la Sierra Boyera. Se trata de terrenos bajos con relieve suave y escasa vegetación, que se encuentran a orillas del embalse de Sierra Boyera. Los materiales son predominantemente terrígenos finos, pero hay también algunos afloramientos de calizas. Estas calizas contienen abundantes corales rugosos y tabulados que han sido muestreados y estudiados.

En la zona de Antolín se han levantado tres secciones por los autores en colaboración con R. Mas:

\section{Antolín 1 (Fig. 4)}

Se encuentra junto al embalse de Sierra Boyera. El afloramiento está formado en parte por una antigua cantera actualmente cubierta por el embalse. La sucesión de calizas masivas de Antolín 1 tiene una potencia de unos 20 metros. La base está constituida por una sucesión de limolitas con intercalaciones de bancos decimétricos de areniscas que quedan truncadas por la base erosiva del litosoma de calizas. Fragmentos de los bancos de areniscas aparecen englobados en la parte inferior de la masa de calizas. Las calizas presentan un carácter marcadamente brechoide. En ellas destacan grandes bloques de caliza arrecifal constituida básicamente por corales rugosos coloniales y algas.

\section{Antolín 2 (Fig. 4)}

Se encuentra en un campo de cultivo de olivos, por lo que los niveles más blandos de la sucesión afloran mal. La base de la sección está surcada por un pequeño riachuelo, que genera un buen afloramiento.

Al igual que en Antolín 1, la litología predominante son brechas calcáreas, con clastos que presentan gran abundancia de fósiles, destacando los corales solitarios y

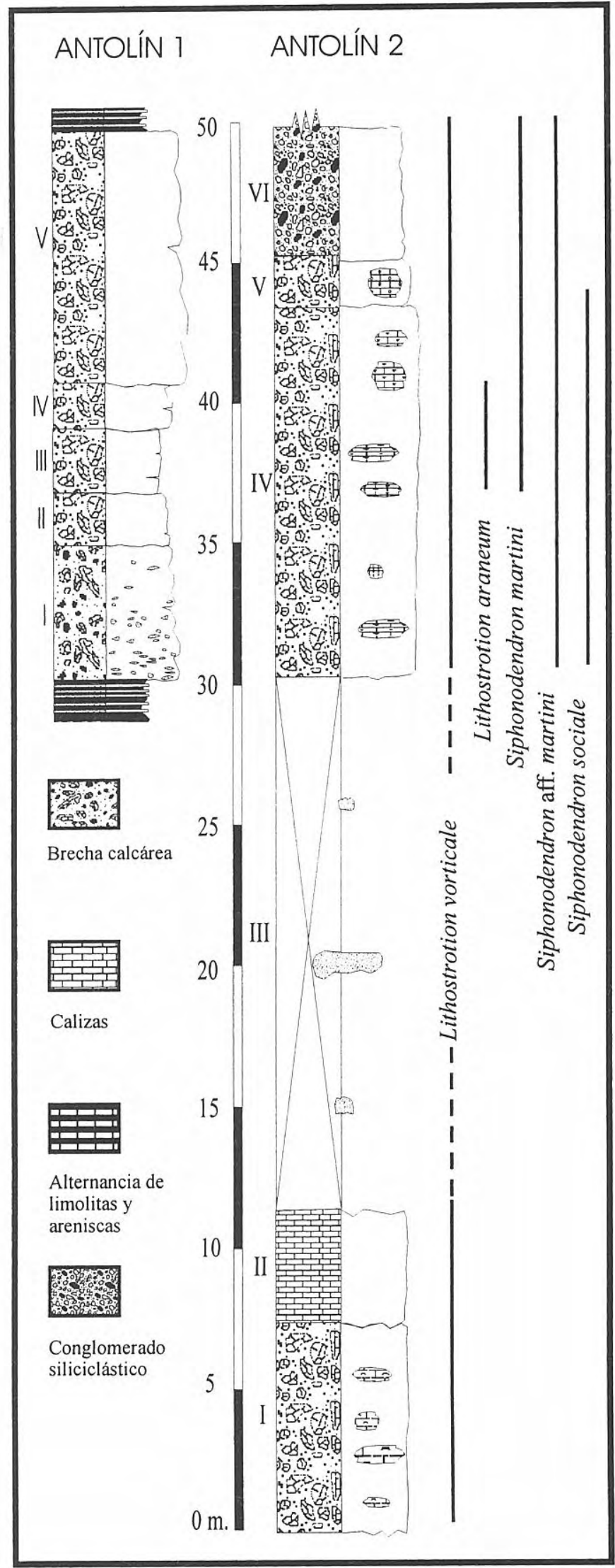

Figura 4. Distribución de los lithostrotiónidos en Antolín. Distribution of lithostrotionid corals in Antolín. 


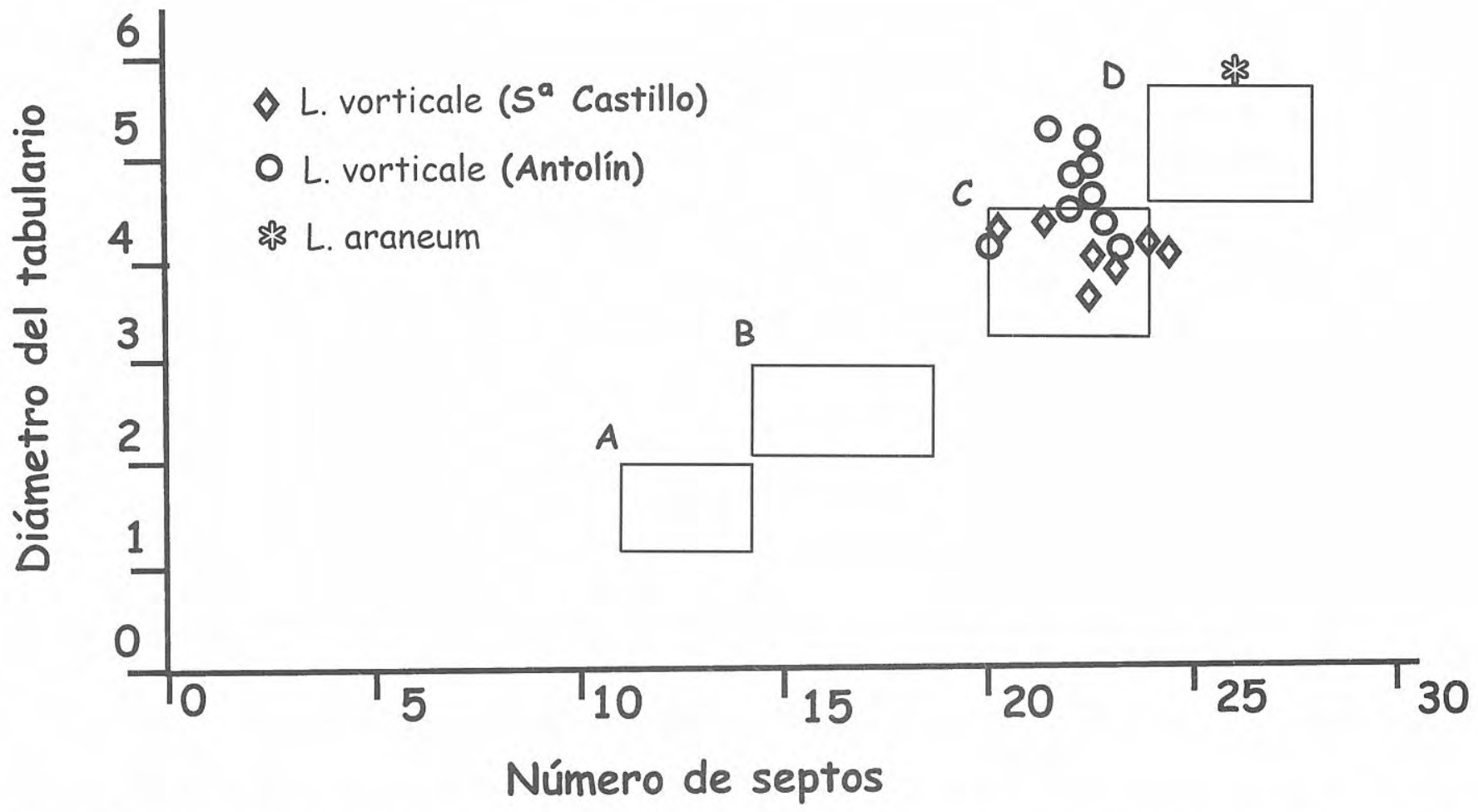

Figura 5. Relación diámetro del tabulario/ $\mathrm{N}^{\circ}$ de septos para las especies de Lithostrotion de la Unidad del Castillo. A.- Ámbito de variabilidad de la especie L. maccoyanum. B.- Ámbito de variabilidad de la especie L. decipiens. C.- Ámbito de variabilidad de la especie L. vorticale. D.- Ámbito de variabilidad de la especie L. araneum.

Tabularium diameter/Number of septa ratio for the species of Lithostrotion from the Castillo Unit. A.- Variability area of L. maccoyanum. B.- Variability area of L. decipiens. C.- Variability area of L. vorticale. D.- Variability area of $\mathrm{L}$. araneum.

coloniales. Los restos son alóctonos en su mayoría, pero algunos fósiles se encuentran entre los litoclastos de la brecha y parecen ser autóctonos o paraautóctonos.

\section{Antolín 3}

Está a orillas del embalse, al sur de los anteriores. En esta localidad no se han diferenciado tramos. En la base del afloramiento se observa un litosoma de brechas calcáreas clastosoportadas, con una potencia total de $5 \mathrm{~m}$ y una extensión lateral de unos $10 \mathrm{~m}$ y con geometría canalizada. Las brechas están constituidas por litoclastos angulosos bioclásticos de tamaño centimétrico a decimétrico. En los laterales y por encima de este litosoma, se reconoce una sucesión limolítica-margosa de unos $20 \mathrm{~m}$ de potencia, bastante continua, en la que se intercalan niveles centimétricos de caliza margosa muy bioclástica con braquiópodos, corales rugosos y crinoides; también se identifican pequeños cuerpos canalizados de escala métrica ( $1 \mathrm{~m})$ compuestos por brechas calcáreas clastosoportadas, con litoclastos bioclásticos de tamaño pebble-cobble. En los niveles limolíticos y margosos se observa una importante bioturbación representada sobre todo por Zoophycos. Los corales son escasos y están casi siempre aplastados, algo fragmentados y con frecuencia presentan signos de decalcificación.

\section{DESCRIPCIÓN SISTEMÁTICA}

En este capítulo se describen los lithostrotiónidos identificados en la unidad de la Sierra del Castillo. Las descripciones son lo más detalladas posible, aunque algunos taxones están representados por pocos ejemplares y no se han podido establecer las posibles variaciones intraespecíficas. Se ha seguido en general la clasificación propuesta por Hill (1981).

En las descripciones de los elementos morfológicos se ha seguido la terminología propuesta por Hill $(1956,1981)$ y completada por Poty (1981), y Rodríguez (1984) para los términos en español. En las descripciones de la microestructura se ha seguido la terminología propuesta por Semenoff-Tian-Chansky (1974), además de las precisiones aportadas por Rodríguez (1984) y Falces (1998).

Se incluyen sinonimias de todos los taxones, pero éstas no son exhaustivas. Se relacionan tan sólo aquellas referencias que hemos considerado importantes por ser determinantes para la comprensión de cada taxón o por representar menciones de interés para las relaciones biogeográficas del área estudiada. Por ello se incluyen casi siempre las primeras citas de cada taxón y las más recientes en la subprovincia del Paleotetis occidental (Europa Occidental, África del Norte).

En las tablas de medidas de las distintas especies se incluyen las siguientes abreviaturas: d.a. $=$ diámetro alar. d.t. 
= diámetro del tabulario. n.s. = número de septos mayores. n.1.= número de lados. Otras abreviaturas usadas en las figuras se explican en las leyendas de las mismas.

SUBCLASE RUGOSA Milne-Edwards y Haime, 1850 ORDEN STAURIIDA Verrill, 1865

SUBORDEN LITHOSTROTIONINA Spassky y

Kachanov, 1971

Familia Lithostrotionidae D’Orbigny, 1852

Subfamilia Lithostrotioninae D'Orbigny, 1852 Género Lithostrotion Fleming, 1828

*1828 Lithostrotion Fleming, 508.

1981 Lithostrotion Fleming; Hill, 379.

1981 Lithostrotion Fleming; Poty, 20.

1990 Lithostrotion Fleming; Vuillemin, 86.

1992 Lithostrotion Fleming; Rodríguez y Falces, 198.

Especie tipo: Lithostrotion striatum Fleming, 1828, por designación original. Igual a L. vorticale (Parkinson, 1808), desde 1931, según decisión de la Comisión Internacional de Nomenclatura Zoológica.

Diagnosis (Según Poty, 1981)

Corales cerioides. Cada coralito tiene una columnilla estiliforme. Septos mayores largos, que llegan hasta la columnilla o hasta sus proximidades. Los menores se limitan al disepimentario y, como mucho, sobrepasan ligeramente su borde interno. Disepimentos simples, numerosos, a veces transeptales. Tabulario estrecho, incompleto por lo general, con tábulas periaxiales planas y subaxiales horizontales o poco inclinadas hacia el disepimentario. Reproducción de tipo intermural no parricida.

\section{Discusión}

En el pasado, el género Lithostrotion se ha utilizado en un sentido más amplio que en la actualidad. En él se incluía el actual género Siphonodendron. Poty (1981) y Hill (1981) asignan las formas cerioides a Lithostrotion y las formas fasciculadas a Siphonodendron. Este criterio ha sido posteriormente seguido por todos los autores que han trabajado en este grupo.

Se han descrito más de ochenta especies de este género, pero, en una revisión de Nudds (1980), la mayoría de ellas fueron puestas en sinonimia. Las especies pertenecientes a este género descritas en Europa occidental se pueden diferenciar por comparación estadística de sus dimensiones y parámetros mensurables. Los caracteres utilizados por Nudds (1980) y Poty (1981) son el número de septos y el diámetro del tabulario. No se utiliza el diámetro alar porque la forma poligonal de los poliperitos en sección transversal plantea muchos problemas para la medición correcta de este parámetro. Las especies descritas en Europa occidental y admitidas por todos los autores son (de mayor a menor tamaño): $L$. araneum (Mc Coy, 1844), L. vorticale (Parkinson, 1808), L. decipiens (Mc Coy, 1849) y L. maccoyanum MilneEdwards y Haime, 1851 (Fig. 5).

\begin{tabular}{|c|c|c|c|c|}
\hline \multicolumn{2}{|c|}{ Siglas } & n.s. & d.t. & n.l. \\
\hline \multirow{3}{*}{$\mathrm{CCS} / 2-1$} & Media & 22.56 & 3.55 & 5.6 \\
\hline & Rango & $18-26$ & $2.46-4.77$ & $5-8$ \\
\hline & $\mathrm{N}^{\circ}$ datos & 41 & 41 & 41 \\
\hline \multirow{3}{*}{$\mathrm{COL} / 13-25$} & Media & 23.95 & 4.18 & 6.17 \\
\hline & Rango & $21-26$ & $3.08-5.08$ & $5-8$ \\
\hline & $\mathrm{N}^{\circ}$ datos & 46 & 46 & 46 \\
\hline \multirow{3}{*}{ COL/13-26 } & Media & 24.51 & 4.05 & 6.81 \\
\hline & Rango & $21-28$ & $2.62-5.69$ & $4-10$ \\
\hline & $\mathrm{N}^{0}$ datos & 131 & 131 & 131 \\
\hline \multirow{3}{*}{ COL/13-27 } & Media & 22.72 & 4.09 & 5.82 \\
\hline & Rango & $19-31$ & $2.92-5.69$ & $4-9$ \\
\hline & $\mathrm{N}^{0}$ datos & 86 & 86 & 86 \\
\hline \multirow{3}{*}{ COL/148 } & Media & 23.33 & 3.91 & 5.96 \\
\hline & Rango & $19-26$ & $3.08-4.77$ & $4-8$ \\
\hline & $\mathrm{N}^{\circ}$ datos & 26 & 26 & 26 \\
\hline \multirow{3}{*}{ SSE/18-1 } & Media & 20.5 & 4.24 & 5.19 \\
\hline & Range & $19-22$ & $3.5-5.0$ & $4-7$ \\
\hline & $\mathrm{N}^{0}$ datos & 26 & 26 & 19 \\
\hline \multirow{3}{*}{$\mathrm{SSE} / 22-1$} & Media & 21.14 & 4.36 & 5.14 \\
\hline & Range & $20-23$ & $4.0-4.9$ & $4-7$ \\
\hline & $\mathrm{N}^{0}$ datos & 7 & 7 & 7 \\
\hline \multirow{3}{*}{ ANT 1/-9 } & Media & 23.38 & 4.38 & 5.6 \\
\hline & Bango & $22-26$ & $3.14-5.7$ & $5-7$ \\
\hline & $\mathrm{N}^{0}$ datos & 8 & 21 & 10 \\
\hline \multirow{3}{*}{ ANT $2 / 1-10$} & Media & 23.2 & 4.31 & 6.25 \\
\hline & Rango & $21-25$ & $3.54-5.38$ & $5-8$ \\
\hline & $\mathrm{N}^{0}$ datos & 5 & 5 & 4 \\
\hline \multirow{3}{*}{ ANT $2 / 1-37$} & Media & 23.06 & 4.54 & 7.51 \\
\hline & Rango & $19-26$ & $3-5.71$ & $4-10$ \\
\hline & $\mathrm{N}^{0}$ datos & 51 & 56 & 49 \\
\hline \multirow{3}{*}{ ANT 2/1-38 } & Media & 23.61 & 4.02 & 5.9 \\
\hline & Rango & $20-27$ & $1.15-6$ & $4-8$ \\
\hline & $\mathrm{N}^{0}$ datos & 61 & 61 & 61 \\
\hline \multirow{3}{*}{ ANT 2/1-64 } & Media & 21.92 & 5.19 & 6 \\
\hline & Rango & $20-24$ & $4.15-6.62$ & $4-8$ \\
\hline & $\mathrm{N}^{\circ}$ datos & 12 & 12 & 9 \\
\hline \multirow{3}{*}{ ANT 2/1-66 } & Media & 23.92 & 5.02 & 5.75 \\
\hline & Rango & $20-27$ & $3.85-5.85$ & $5-7$ \\
\hline & $\mathrm{N}^{0}$ datos & 13 & 15 & 12 \\
\hline \multirow{3}{*}{ ANT 2/1-68 } & Media & 20.5 & 4.15 & 5.4 \\
\hline & Rango & $18-24$ & $3.23-4.92$ & $5-6$ \\
\hline & $\mathrm{N}^{0}$ datos & 6 & 9 & 5 \\
\hline \multirow{3}{*}{ ANT 2/1-71 } & Media & 23.22 & 4.99 & 5.67 \\
\hline & Rango & $21-25$ & $3.08-6.46$ & $4-8$ \\
\hline & $\mathrm{N}^{0}$ datos & 9 & 9 & 9 \\
\hline \multirow{3}{*}{ ANT $2 / 1-72$} & Media & 22.4 & 4.42 & 5.25 \\
\hline & Rango & $20-24$ & $3.08-5.38$ & $4-6$ \\
\hline & $\mathrm{N}^{0}$ datos & 5 & 9 & 4 \\
\hline \multirow{3}{*}{ ANT $2 / 4-4$} & Media & 22.67 & 4.83 & i? \\
\hline & Range & $21-24$ & $3.69-5.85$ & \\
\hline & $\mathrm{N}^{0}$ datos & 13 & 7 & \\
\hline \multirow{3}{*}{ ANT $3 /-1^{\prime}$} & Media & 27 & 4.61 & 6 \\
\hline & Rango & $25-28$ & $4.46-4.92$ & $5-7$ \\
\hline & $\mathrm{N}^{0}$ datos & 6 & 6 & 5 \\
\hline
\end{tabular}

Tabla 1. Medidas en algunos ejemplares de Lithostrotion vorticale.

Measurements in some specimens of Lithostrotion vorticale.

El género Siphonodendron parece presentar dos líneas evolutivas: una de ellas está caracterizada por una reducción en el diámetro y número de septos, e incluso por la desaparición de los disepimentos. Esta línea está representada por la sucesión $S$. martini $->S$. irregulare $>S$. pauciradiale - $>S$. junceum. La otra línea muestra un incremento en el diámetro alar y en el número de septos (Poty, 1984). Esta última tendencia está representada por la línea $S$. martini $->S$. sociale $->S$. scaleberense. 


\section{Lithostrotion vorticale (Parkinson, 1808)} Tabla 1; Figs. 5-7

*1808 Madrepora vorticalis Parkinson, 45, lám. 5, figs. 3-6.
1828 Lithostrotion striatum Fleming, 508.
1849 Nemaphyllum minus Mc Coy, 17.
1940 Lithostrotion clavaticum Thomson; Hill, 176, lám. 9,
figs. 15-21; lám. 10, fig. 1.
1981 Lithostrotion vorticale (Parkinson); Poty, 22, lám. 5,
figs. 1-4. 1992 Lithostrotion vorticale (Parkinson); Rodríguez y Falces, 200-201, lám. 18, fig. 4.

Material estudiado: 22 colonias (COL/2 ${ }^{\mathrm{a}}-3$; COL/13-25; COL/13-26; COL/13-27; COL/14-8; CCS/2-1, SSE/18-1, SSE/21-6, SSE/22-1, ANT1/-9; ANT 2/1-10; ANT 2/1-28; ANT 2/1-37; ANT 2/1-38; ANT 2/1-64; ANT 2/1-66; ANT 2/1-67; ANT 2/1-68; ANT 2/1-71; ANT 2/1-72; ANT 2/4-4; ANT 3/-1'). Unas cincuenta secciones transversales y 25 secciones longitudinales más tres láminas ultrafinas.

\section{Diagnosis (según Poty, 1981)}

Lithostrotion cuyos poliperitos tienen 20 septos de media en cada ciclo y un máximo de 24 y el tabulario de 3,3 a $4,1 \mathrm{~mm}$ de diámetro medio.

\section{Descripción}

Caracteres externos: Corales coloniales masivos cerioides (Fig. 6a-f). Al menos dos de los ejemplares de la Sierra de la Estrella (SSE/18-1 y SSE/21-6) muestran zonas de la colonia con tendencia fasciculada parcialmente desarrollada (Fig. 6h, i). En estos ejemplares se produce también una amplia variación en el tamaño de los individuos. Esto se debe a un número muy elevado de individuos juveniles con relación al total de la colonia. En el cuadro de medidas no se muestran estos individuos, que por ser juveniles modificarían a la baja las medias de las dimensiones de la colonia (Tabla 1).

Caracteres internos: Poliperitos poligonales, de 4 a 7 lados. Las medias del diámetro del tabulario de las colonias oscilan entre 3,55 y 4, $18 \mathrm{~mm}$ (Fig. 5, Tabla 1 ).

La muralla es simple y fina. Los septos mayores son largos, finos y algo engrosados en el tabulario, rectos y con disposición radial. El número medio de septos mayores está comprendido entre 22,56 y 24,51. La gran mayoría de ellos se unen a la columnilla, observándose que próximos a ella presentan una tendencia sinuosa y fasciculada. Los septos menores son cortos, rectos y finos, con una longitud ligeramente mayor o igual a la anchura del disepimentario (Fig. 6a-c).

El disepimentario es ancho y sus filas son numerosas (4 a 6). Los disepimentos son interseptales, regulares o esporádicamente entrecruzados y finos. La fila más interna del disepimentario está engrosada y forma una disepiteca, que es más notable en algunos ejemplares de Antolín (Fig. 6f). En sección longitudinal son alargados o semi-globosos y con una inclinación que varía desde vertical hasta moderada.

Las tábulas en sección longitudinal son mayoritariamente incompletas, constituidas por 1 a 4 tabelas, pero también pueden ser completas. Son horizontales en la zona cercana al disepimentario y verticales o con una inclinación moderada hacia la periferia cerca de la columnilla, para unirse a ésta con morfologías cónicas (Fig. 6d-e).

La columnilla es simple y se forma por engrosamiento y alargamiento del septo antípoda. La morfología puede variar de elipsoidal a circular en sección; esta última en menor proporción, aunque en algunas colonias de Antolín puede ser mayoritaria. Pocas veces se une la columnilla con el septo cardinal.

\section{Microestructura}

La microestructura de los septos es granulo-fibrosa; las fibras forman a veces trabéculas, aunque no completamente estructuradas. Los disepimentos y tábulas son microgranulares. La columnilla presenta una zona interna formada por trabéculas de la que parten una serie de fascículos de fibras laterales que no llegan a constituir trabéculas completas. La muralla es microlamelar, con elementos hialinos en la zona de contacto entre los individuos. El estereoplasma es lamelar y su desarrollo mínimo o nulo (Fig. 6g, 7).

\section{Discusión}

Las dimensiones y características de los ejemplares de Lithostrotion vorticale de la Sierra del Castillo coinciden con las descritas por Nudds (1980) y Poty (1981) para los ejemplares de Gran Bretaña y Bélgica, y por Rodríguez y Falces (1992) para los ejemplares de la cuenca de Los

Figura 6. Lithostrotion vorticale (Parkinson, 1808). a: SSE/18-1. Sección transversal de una zona cerioide de una colonia con áreas pesudofasciculadas, x3. b: SSE/22-1. Sección transversal de una parte inicial de una colonia que muestra múltiples individuos juveniles, x3. c: ANT 2/ 1-37. Sección transversal, x 3. d: ANT 2/ 1-37. Sección longitudinal, x3. e: ANT 1/ -9. Sección longitudinal, x3. f: ANT 2/ 1-10. Sección transversal, x 3. g: COL/2a-3. Microestructura de la muralla y del arranque de los septos. X 70. h: SSE/18-1. Sección transversal de una zona pseudofasciculada que pese a la separación de los poliperitos muestra tendencia a formas poligonales, x3. i: SSE/18-1. Sección transversal de una colonia mostrando el tránsito entre la zona cerioide (derecha) y la zona pseudofasciculada (izquierda), x3.

a: SSE/18-1. Transverse section of a cerioid zone of a pseudofasciculate colony, x3. $b$ : SSE/22-1. Transverse section of a colony showing many young corallites, x3. c: ANT 2/ 1-37. Transverse section, x 3. d: ANT $2 / 1-37$. Longitudinal section, x3. e: ANT 1/ -9. Longitudinal section, x3. f: ANT 2/ 1-10. Transverse section, x 3. g: COL/2a3. Microstructure of the wall and the basal portion of some septa. x70. $h$ : SSE/18-1: Transverse section of a pseudofasciculate colony showing separate but polygonal corallites, $x 3$. $i$ : SSE/18-1. Transverse section of a pseudofasciculate colony showing the transitional area between cerioid (right) and fasciculate zones (left), x3. 

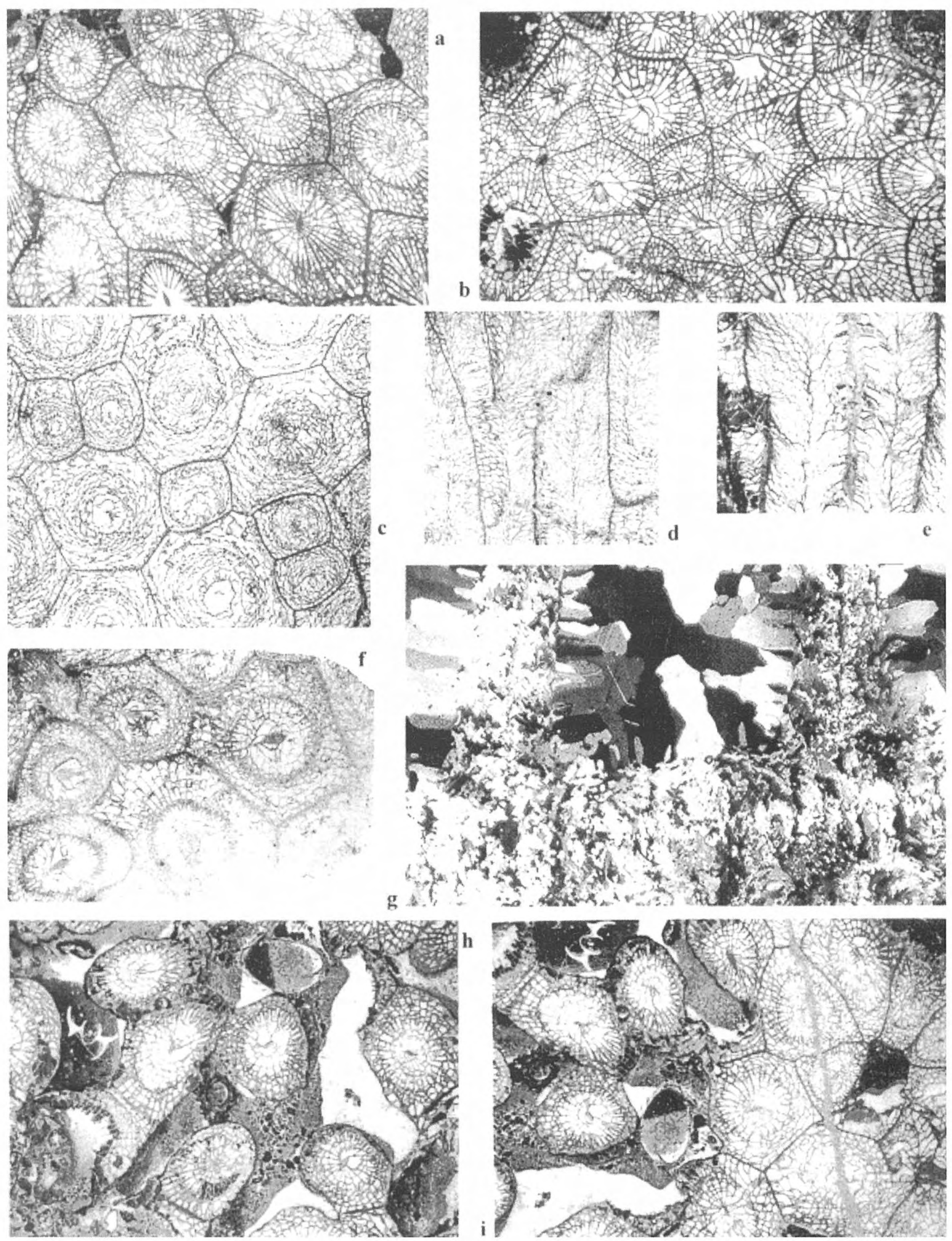

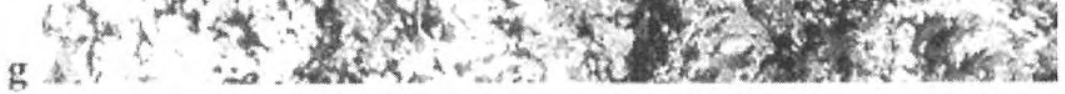

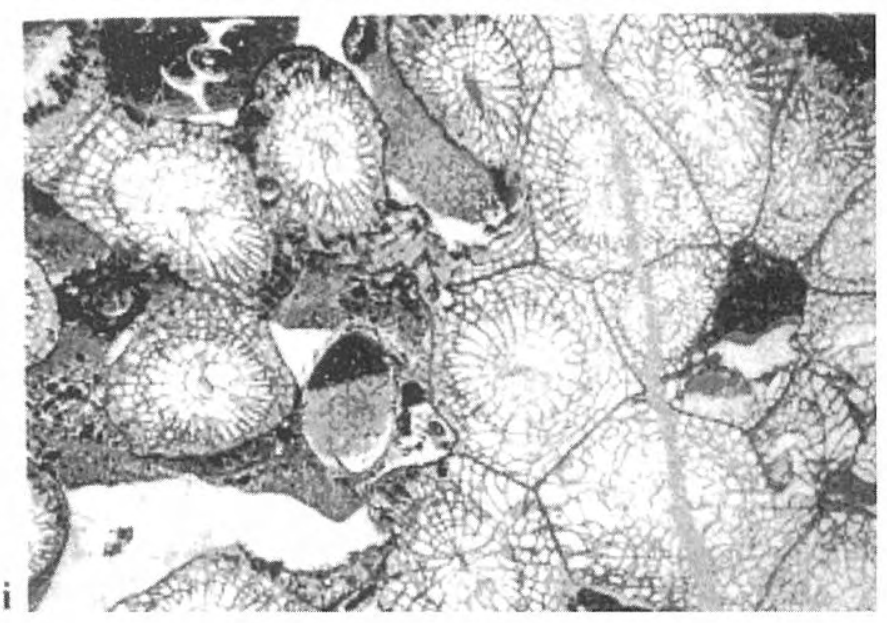




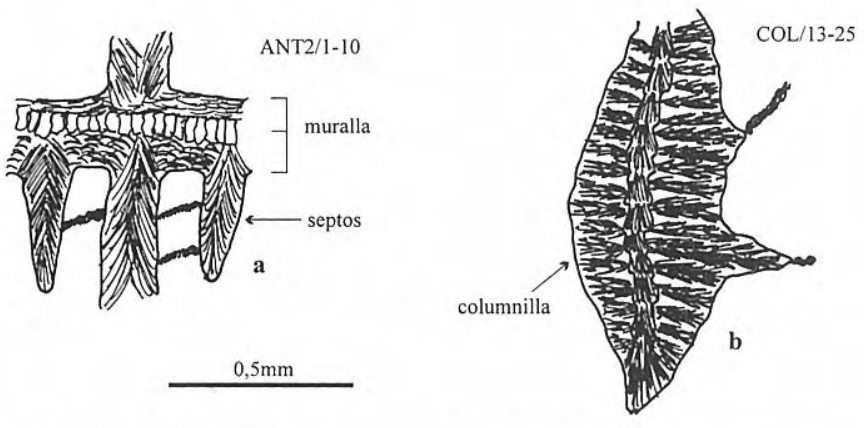

Figura 7. Microestructura de Lithostrotion vorticale. a: Muralla y base de los septos. b: columnilla axial. Microstructure of Lithostrotion vorticale. a: Wall and base of some septa. $\boldsymbol{b}$ : Axial column.

Santos de Maimona en España. El diámetro del tabulario de los ejemplares descritos está próximo a la media de los ejemplares de Bélgica y Gran Bretaña, mientras que el número de septos queda en el límite superior indicado por Nudds (1980) y Poty (1981) (Fig. 5). El valor menor de la relación diámetro $/ \mathrm{n}^{\circ}$ de septos es una característica común con los ejemplares de esta especie de la Cuenca de Los Santos de Maimona.

En los ejemplares de Antolín se ha detectado una tendencia a presentar estructuras más densas, con la presencia de una disepiteca muy pronunciada, una lámina media bastante engrosada y un diámetro del tabulario mayor de lo normal (Fig. 6f), con algunos ejemplares que se saldrían de la variación establecida para la especie (Fig. 5). Estas diferencias podrían deberse a las especiales condiciones ambientales detectadas en las sucesiones de esta localidad, por lo que no se han estimado suficientes para considerar ninguna diferencia taxonómica.

La variante con zonas pseudofasciculadas de la Sierra de la Estrella se incluye en el género Lithostrotion porque las fases iniciales de las colonias son claramente cerioides y sólo en un determinado momento de su desarrollo llegan a ser faceloides. En ello se diferencian de las formas de Siphonodendron descritas por Poty (1981) ya que éstas tienen unas fases iniciales faceloides y sólo en fase adulta llegan a ser subcerioides. Esta variante se debe probablemente al crecimiento en una zona con momentos desfavorables para el desarrollo de Lithostrotion. Esto se refleja en una multiplicación de individuos más rápida de lo habitual, con alta frecuencia de individuos juveniles, y en el desarrollo de zonas menos densamente empaquetadas (Fig. 6h-i). Las zonas pseudofaceloides de estas colonias se relacionan con mayor cantidad de terrígenos en los sedimentos circundantes. En cualquier caso, esta situación parece demostrar tanto la relación de parentesco de Lithostrotion y Siphonodendron (los ejemplares del primero, en condiciones de estrés, remedan formas del segundo) como la diferencia real de estos dos géneros que ha sido puesta en duda por algunos autores (pese al desarrollo pseudofascicular, no llega a producirse una vuelta atrás y la colonia sigue siendo mayoritariamente cerioide; si las condiciones favorables vuelven a producirse, el coral vuelve a desarrollar una forma cerioide no anómala).

\begin{tabular}{|c|c|c|c|c|}
\hline \multicolumn{2}{|c|}{ Siglas } & n, s, & d, t, & n, l, \\
\hline \multirow{4}{*}{ ANT 1/-25 } & Media & 26,25 & 5,88 & 6 \\
\cline { 2 - 5 } & Rango & $24-28$ & $4,92-7,08$ & $4-8$ \\
\cline { 2 - 5 } & $\mathbf{N}^{0}$ datos & 24 & 25 & 17 \\
\hline
\end{tabular}

Tabla 2. Medidas en Lithostrotion araneum. Measurements in Lithostrotion araneum.

\section{Lithostrotion araneum (Mc Coy, 1844)} Tabla 2; Figs. 5, 8

*1844 Astraea aranea Mc Coy, 187.

1981 Lithostrotion araneum (Mc Coy); Poty, 20, lám. 4. 1992 Lithostrotion araneum (Mc Coy); Rodríguez y Falces, 198.

Material: Un ejemplar del que se han hecho dos secciones transversales y dos longitudinales. ANT1/-25.

\section{Diagnosis (Según Poty, 1981)}

Cerioide. Coralitos grandes, con una media de 23 a 26 septos en cada ciclo y como máximo 31. Disepimentario grande, formado por disepimentos simples, entrecruzados o arqueados. El diámetro del tabulario es de 4,5 a 5,3 mm de media.

\section{Descripción}

Caracteres externos: Coloniales masivos, cerioides.

Caracteres internos: Los individuos presentan murallas no compartidas, finas y lisas a festoneadas. Pueden tener importantes variaciones de grosor. El diámetro del tabulario se aproxima a los $6 \mathrm{~mm}$ en la mayoría de los individuos y su número de septos oscila alrededor de 27 (Fig. 5, Tabla 2).

El disepimentario es interseptal, concéntrico y regular. Se cuentan de 10 a 12 filas de disepimentos regulares, en algún caso entrecruzados, hasta la disepiteca. En corte longitudinal los disepimentos son globosos y tienen una inclinación menor en la zona periférica del coral (Fig. 8).

Los septos son largos, rectos y, en ocasiones, ligeramente sinuosos. Los de primer orden, por lo general, se afinan en su extremo axial y se engrosan en la zona del tabulario. Los de segundo orden se engrosan en su borde axial y presentan una longitud que alcanza la mitad de la de los de primer orden. Alguno de los septos está unido a la estructura axial.

En corte longitudinal, las tábulas son cónicas y en la zona pericolumnar adoptan una tendencia cóncava. La estructura axial es simple, lanceolada, en forma de lamela engrosada. Las láminas medias de los distintos individuos de la colonia no están orientadas en una misma dirección. El septo cardinal y el antípoda están, por lo general, unidos a la columnilla, aunque en ocasiones sólo lo está el antípoda (Fig. 8).

\section{Microestructura}

Septos con microestructura fibrosa en "chorro de agua", aunque en algunas zonas se insinúan trabéculas incipientes. Prácticamente no hay estereoplasma. Muralla lamelar con elementos hialinos en la zona de contacto entre los individuos. Disepimentos granulares. Los engrosamientos de 

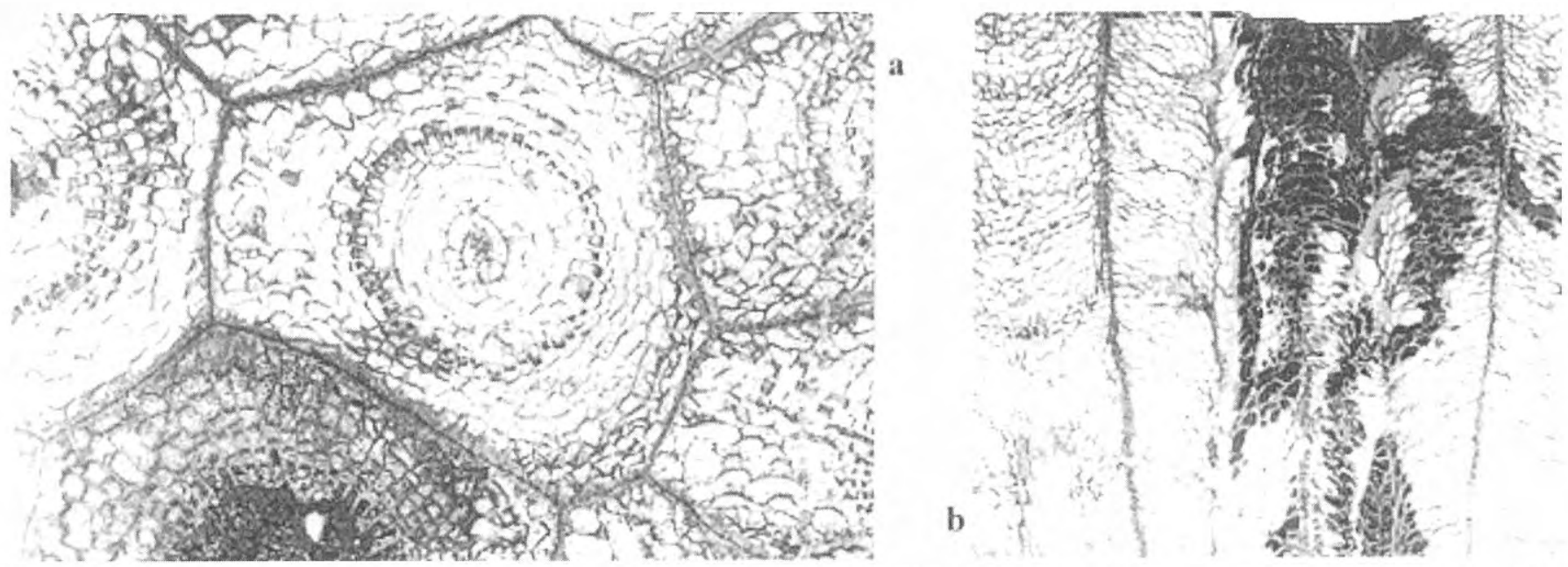

Figura 8. Lithostrotion araneum Mc Coy, 1844. a: ANT 1/-25. Sección transversal, x3. b: ANT 1/-25. Sección longitudinal, $\mathrm{x} 3$.

a: ANT 1/-25. Transverse section, x3. b: ANT 1/-25. Longitudinal section, x3.

los septos y disepimentos son lamelares, aunque resultan muy escasos.

\section{Discusión}

El ejemplar estudiado presenta características que pueden incluirse en el ámbito de variabilidad de $L$. araneum. Se diferencia de los ejemplares británicos y belgas de esta especie tan sólo en sus dimensiones. Nuestro ejemplar presenta un diámetro del tabulario algo mayor de lo habitual (Fig. 5), y es muy semejante a los ejemplares de la misma especie descritos en Los Santos de Maimona (Rodríguez y Falces, 1992).

\section{Género Siphonodendron McCoy, 1849}

*1849 Siphonodendron McCoy. 127.

1981 Siphonodendron McCoy; Hill, 381.

1981 Siphonodendron McCoy; Poty, 26.

1990 Siphonodendron McCoy; Vuillemin, 88.

1992 Siphonodendron McCoy; Rodríguez y Falces, 202.

Especie tipo: Lithodendron pauciradialis Mc Coy, 1844.

Diagnosis (según Poty, 1981)

Polípero fasciculado, con coralitos que presentan columnilla estiliforme. Septos mayores de longitud variable, que pueden llegar o no a la columnilla. Los menores están más o menos desarrollados, se limitan al disepimentario, pudiendo sobrepasarlo ligeramente. Disepimentario bien desarrollado, y formado por disepimentos simples, ausentes en las formas muy pequeñas. Tábulas completas o algo divididas, cónicas. Forman en las cercanías del disepimentario un canalón. Reproducción de tipo lateral y no parricida, excepto en alguna especie rara, en la que puede ser periférico y parricida.

\section{Discusión}

El género Siphonodendron es probablemente el más frecuente en el Viseense de todo el mundo y especialmente de la provincia mediterránea, que comprende toda Europa occidental. Se han descrito más de cincuenta especies asignadas a este género. Intentos de esclarecer la identificación especifica de los diferentes miembros de este género se encuentran en los trabajos de Nudds (1980), Poty (1981 y 1984) y Nudds y Somerville (1987). Las especies de Siphonodendron descritas en Europa occidental y aceptadas por todos los autores son, de menor a mayor tamaño: S. junceum (Fleming, 1828); S. pauciradiale (Mc Coy, 1844); S. irregulare (Phillips, 1836); S. intermedium Poty, 1981; S. martini (MilneEdwards y Haime, 1851); S. sociale (Phillips, 1836); S. scaleberense Nudds y Somerville, 1987 y S. multiradiale Nudds y Somerville, 1987 (Fig. 9). Estas especies se diferencian principalmente en el número de septos y en las dimensiones del diámetro alar y del tabulario. La variabilidad de los ejemplares de la Sierra del Castillo y de la Sierra de la Estrella entra dentro de las características y dimensiones de los ejemplares descritos en Gran Bretaña, Irlanda y Bélgica por los autores anteriormente citados. Aunque el número de septos, por lo general, está próximo al límite superior de cada especie, no ocurre lo mismo con el diámetro alar, el cual está próximo a la media de cada especie. Esta relación diámetro/número de septos menor de lo habitual es una característica común de los ejemplares de la Sierra del Castillo y la Sierra de la Estrella con los ejemplares de Los Santos de Maimona (Rodríguez y Falces, 1992). Las causas de este valor menor pueden ser paleobiogeográficas o paleoecológicas. Por el contrario, los ejemplares de este género que se encuentran en Antolín presentan unas características especiales, con un número de septos muy elevado para su diámetro (semejante por otra parte al de $S$. martini) y con una densidad de estructuras muy alta. En esto se asemejan en cierta medida a la especie $S$. multiradiale, que presenta un diámetro que se solapa con el de las especies $S$. sociale y S. scaleberense, pero que posee un número de septos mucho más alto. Este carácter parece estar relacionado con las condiciones ambientales. 


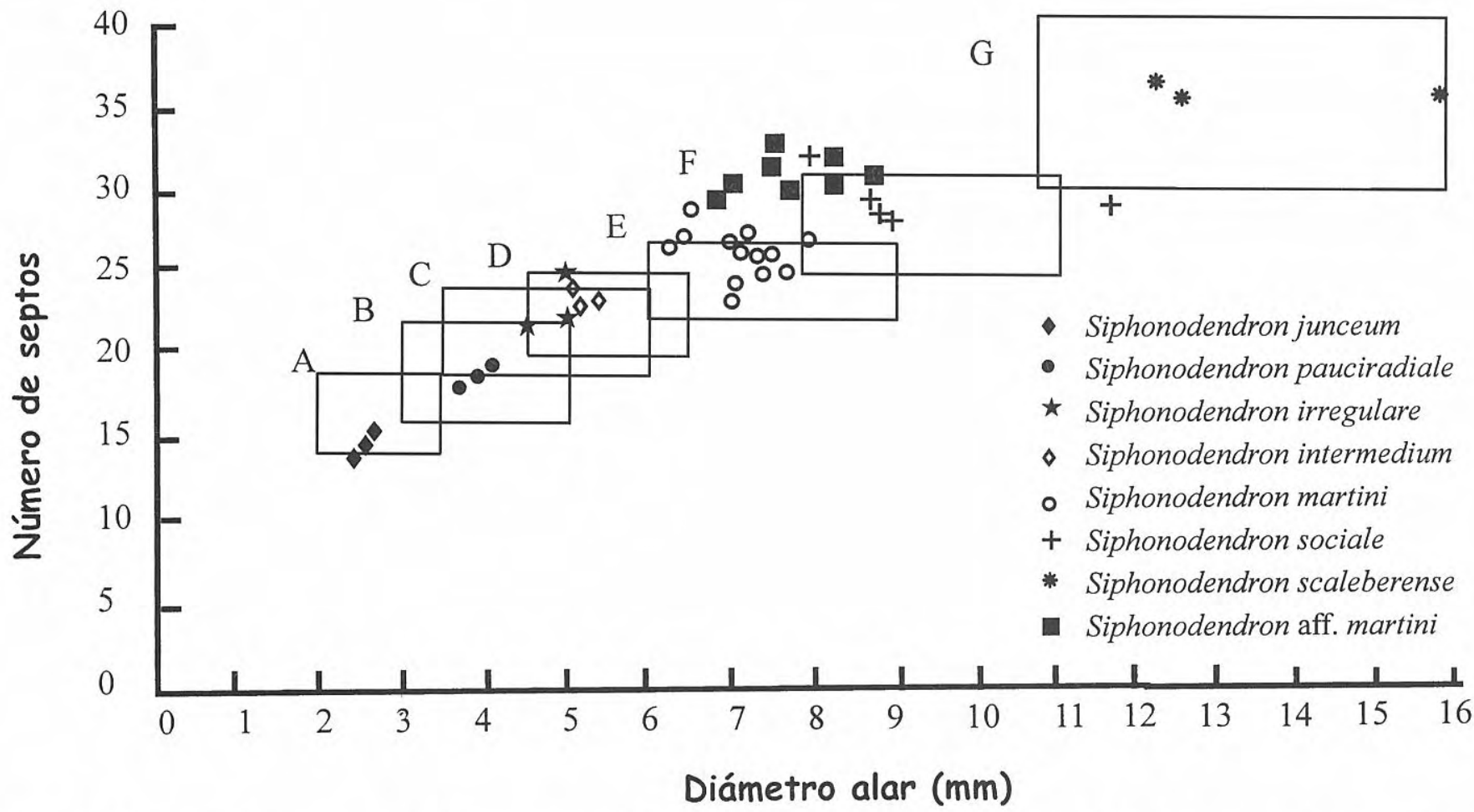

Figura 9. Relación diámetro alar/ $\mathrm{N}^{\circ}$ de septos en Siphonodendron. A. Ámbito de variabilidad de S. junceum (Fleming, 1828); B. Ámbito de variabilidad de S. pauciradiale (Mc Coy, 1844); C. Ámbito de variabilidad de S. irregulare (Phillips, 1836); D. Ámbito de variabilidad de S. intermedium Poty, 1981; E. Ámbito de variabilidad de S. martini (MilneEdwards y Haime, 1851); F. Ámbito de variabilidad de $S$. sociale (Phillips, 1836); G. Ámbito de variabilidad de $S$. scaleberense Nudds y Somerville, 1987.

Alar diameter/Number of septa ratio in Siphonodendron. A. Variability area of S. junceum (Fleming, 1828$)$; B. Variability area of S. pauciradiale (Mc Coy, 1844); C. Variability area of S. irregulare (Phillips, 1836); D. Variability area of S. intermedium Poty, 1981; E. Variability area of S. martini (Milne- Edwards and Haime, 1851); F. Variability area of S. sociale (Phillips, 1836); G. Variability area of S. scaleberense Nudds and Somerville, 1987.

\section{Siphonodendron junceum (Fleming, 1828)} Tabla 3; Figs. 9-11

*1828 Caryophyllia juncea Fleming, 508.

1940 Lithostrotion junceum (Fleming); Hill, 171-173, lám. 9, figs. 3-8.

1981 Siphonodendron junceum (Fleming); Poty, 32, lám. 13, fig. 1.

1991 Siphonodendron junceum (Fleming); Fontaine et al., 46.

Material estudiado: Se han estudiado tres colonias (COL/13-22; COL/13-23 y CCS/11-1).

Diagnosis (según Poty, 1981)

Especie de Siphonodendron cuyos poliperitos tienen un diámetro medio entre 2,3 y $3 \mathrm{~mm}$. Los septos menores son rudimentarios o no están presentes. Los septos mayores alcanzan una media de 14 a 18 y, como máximo, 20. La columnilla puede estar presente o no. El crecimiento es lateral. No hay disepimentos.

\section{Descripción}

Caracteres externos: Colonias fasciculadas faceloides con individuos muy pequeños. Las colonias en sí alcanzan dimensiones de más de $30 \mathrm{~cm}$ de diámetro y $15 \mathrm{~cm}$ de altura.

\begin{tabular}{|c|c|c|c|c|}
\hline \multicolumn{2}{|c|}{ Siglas } & N s. & d. t. & d. a. \\
\hline \multirow{4}{*}{ CCS/11-1 } & Media & 14,47 & 12,48 & 12,48 \\
\cline { 2 - 5 } & Rango & $12-16$ & $1,85-2,92$ & $1,85-2,92$ \\
\cline { 2 - 5 } & $\mathbf{N}^{0}$ datos & 31 & 31 & 31 \\
\hline \multirow{4}{*}{ COL/13-22 } & Media & 16,58 & 2,72 & 2,72 \\
\cline { 2 - 5 } & Rango & $15-19$ & $2,08-3,38$ & $2,08-3,38$ \\
\cline { 2 - 5 } & $\mathbf{N}^{0}$ datos & 22 & 22 & 22 \\
\hline \multirow{4}{*}{ COL/13-23 } & Media & 15,85 & 2,51 & 2,51 \\
\cline { 2 - 5 } & Rango & $13-19$ & $2,00-3,08$ & $2,00-3,08$ \\
\cline { 2 - 5 } & $\mathbf{N}^{0}$ datos & 83 & 83 & 83 \\
\hline
\end{tabular}

Tabla 3. Medidas en algunos ejemplares de Siphonodendron junceum.

Measurements in some specimens of Siphonodendron junceum. 


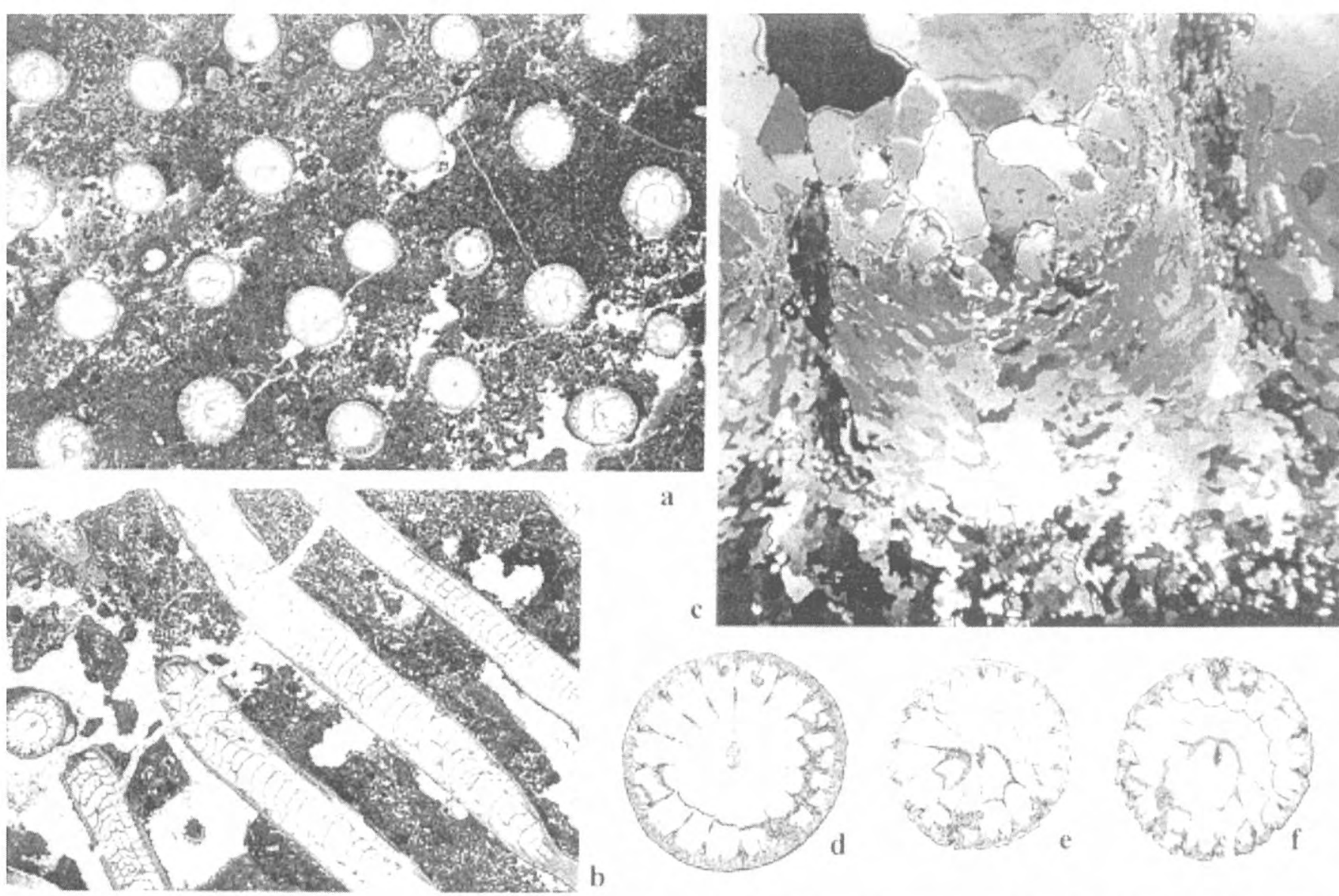

Figura 10. Siphonodendron junceum (Fleming, 1828). a: CCS/11-1. Sección transversal, x3. b: CCS/11-1. Sección longitudinal, x3. c: Microestructura de la muralla y los septos, x280. d: CCS/11-1. Detalle de la sección transversal, x10. e, f: COL/13-22. Detalle de secciones transversales con constricciones en la muralla, x10. a: CCS/11-1. Transverse section, x3. b: CCS/11-1. Longitudinal section, x3. $c$ : Microstructure of the wall and the septa, x280. d: CCS/11-1. Detail of a transverse section, x10. e, f. COL/13-22. Detail of transverse sections showing wall constrictions, $x 10$.

Caracteres internos: Los valores medios del diámetro de los individuos en cada colonia varían entre 2,48 y $2,51 \mathrm{~mm}$ (Figs. 9, 10, Tabla 3).

La muralla es simple, lisa y suele estar ligeramente engrosada. En la colonia hallada en la Cantera del Castillo, la muralla presenta constricciones en número y posición variable. No tienen disepimentos. Los septos mayores son finos, rectos, cortos y con disposición radial, aunque esporádicamente pueden aparecer septos largos que se unen a la columnilla y presentan una tendencia sinuosa y fasciculada. Los septos menores son muy cortos, rectos y finos. Localmente pueden estar ausentes (Fig. 10).

En corte transversal, se aprecian 1 o 2 filas de tábulas finas, de las cuales, la más externa puede estar ligeramente engrosada. En corte longitudinal, las tábulas son completas, finas y simétricas. Son subhorizontales en la zona axial y moderadamente inclinadas hacia la muralla en las proximidades de ésta. La media del número de tábulas por cm es 19,6.

La columnilla puede estar ausente en algunos ejemplares, al menos parcialmente; cuando aparece es simple, laminar o redondeada y fina. Se forma por alargamiento y engrosamiento del septo antípoda.

\section{Microestructura}

La microestructura de la muralla, septos y engrosamientos es microlamelar. Las tábulas son microgranulares. No hay diferenciación de mesoplasma y estereoplasma (Fig. 10c, 11).

\section{Discusión}

Siphonodendron junceum se diferencia básicamente de las demás especies de Siphonodendron por un diámetro alar menor y por la ausencia de disepimentos (Nudds, 1980; Poty, 1981). Entre los ejemplares de la Unidad de la Sierra del Castillo hay una cierta variabilidad, pero todos presentan características típicas de esta especie. Su microestructura se describe aquí por primera vez y cabe resaltar que resulta algo diferente a la del resto de especies del género. Sin embargo, el carácter microlamelar de su microestructura encaja con las hipótesis de Poty (1984) acerca de su origen. La microestructura lamelar se da en estados juveniles de otras especies de Siphonodendron que cuando llegan a estados adultos son predominantemente fibrosos. Dado que esta especie se supone derivada de otra especie de mayor tamaño (probablemente S. pauciradiale), 


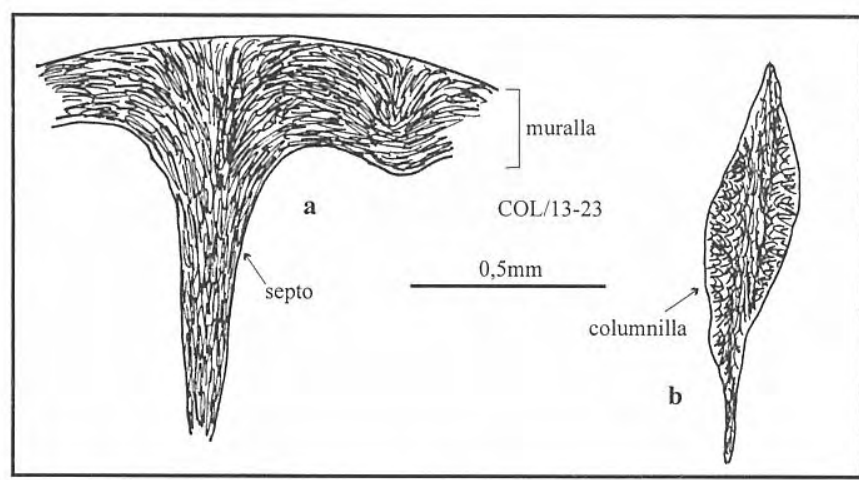

Figura 11. Microestructura de Siphonodendron junceum. a: Muralla y arranque de los septos. b: lámina media.

a: Wall and septal base microstructure. $\boldsymbol{b}$ : medial plate microstructure.

estaríamos frente a un caso de pedomorfosis. Esto coincide con los caracteres macroestructurales de la especie, que también se asemejan a estados juveniles de otras del género.

Aunque se han estudiado tan sólo tres colonias, la especie es frecuente en el nivel 13 de la sección del Collado, donde destaca su asociación con Lithostrotion vorticale. La presencia de una asociación semejante se ha descrito en el Brigantiense de Gran Bretaña.

\section{Siphonodendron pauciradiale (Mc Coy, 1844)} Tabla 4; Fig. 12

*1844 Lithodendron pauciradialis Mc Coy, 189, lám. 27, fig. 7.

1849 Siphonodendron pauciradiale (Mc Coy); Mc Coy, 1.

1850 Lithostrotion pauciradiale (Mc Coy); Milne-Edwards y Haime, 436.

1851 Siphonodendron aggregatum Mc Coy, 108.

1940 Lithostrotion pauciradiale (Mc Coy); Hill, 169, lám. 9, fig. 1, 2.

1981 Siphonodendron pauciradiale (Mc Coy); Poty, 31, lám. 12, fig. 5,6 .

Material: Tres ejemplares (SSE/18-8, SSE/18-9 y SSE/241). Una decena de láminas transversales y longitudinales.

Diagnosis (según Poty, 1981)

Colonias dendroides o faceloides. Poliperitos de 3,7 a 4,3 mm de diámetro medio en cada colonia, que poseen una media entre 18 y 20 y un máximo de 20 septos de cada ciclo. Disepimentario que contiene de 1 a 4 filas de disepimentos. Gemación lateral.

\section{Descripción}

Caracteres externos: Colonias fasciculadas con tendencias dendroides y disposición irregular de los poliperitos. El tamaño de las colonias es pequeño. Aunque en algunos casos se trata de fragmentos, no parece que en ningún caso superen los $10 \mathrm{~cm}$ de diámetro. Presentan gemaciones laterales (Fig. 12).

\begin{tabular}{|c|c|c|c|c|}
\hline \multicolumn{2}{|c|}{ Siglas } & n. s. & d. t. & d. a. \\
\hline \multirow{4}{*}{ SSE/18-8 } & Media & 17,88 & 2,96 & 3,74 \\
\cline { 2 - 5 } & Rango & $17-20$ & $2,5-3,4$ & $3,3-4,4$ \\
\cline { 2 - 5 } & $\mathbf{N}^{\circ}$ datos & 18 & 18 & 18 \\
\hline \multirow{4}{*}{ SSE/18-9 } & Media & 19,62 & 3,38 & 4,06 \\
\cline { 2 - 5 } & Rango & $18-21$ & $2,7-4,2$ & $3,2-5,0$ \\
\cline { 2 - 5 } & $\mathbf{N}^{\circ}$ datos & 32 & 32 & 32 \\
\hline \multirow{4}{*}{ SSE/24-1 } & Media & 18,00 & 3,15 & \\
\cline { 2 - 5 } & Rango & $17-19$ & $2,8-3,5$ & $3,6-4,3$ \\
\cline { 2 - 5 } & $\mathbf{N}^{0}$ datos & 6 & 6 & 6 \\
\hline
\end{tabular}

Tabla 4. Medidas en algunos ejemplares de Siphonodendron pauciradiale.

Measurements in some specimens of Siphonodendron pauciradiale.

Caracteres internos: Muralla fina y lisa. Poseen una única fila de disepimentos interseptales regulares de pequeño tamaño, que en sección longitudinal son verticales. Los septos mayores son cortos y no suelen alcanzar el eje. Los menores se reducen a pequeñas espinas septales sobre la muralla, que rebasan ligeramente la fila de disepimentos. No se aprecia fósula cardinal y el septo cardinal suele estar indiferenciado. El antípoda suele ser más largo y se une a la columnilla. Ésta es una simple lámina media fina, discontinua en algunos ejemplares.

Las tábulas son convexas a cónicas dependiendo del desarrollo de la columnilla. Son finas y medianamente espaciadas (Fig. 12).

\section{Microestructura}

La microestructura de la muralla es lamelar. Los septos son fibrosos, sin diferenciación de fases (water jet o jet d'eau). Los disepimentos y tábulas son microgranulares. Los engrosamientos sobre los disepimentos, tábulas y septos son microlamelares.

\section{Discusión}

Los ejemplares de la Sierra de la Estrella son muy característicos de $S$. pauciradiale. No sólo coinciden en las dimensiones, sino que presentan una típica irregularidad en el desarrollo de las colonias. Este es un carácter que algunos autores han querido relacionar con las reducidas dimensiones, pero que no se produce en $S$. junceum que presenta dimensiones aún menores. Esta especie parece adaptada a medios no tan favorables como otras especies del mismo género, ya que aparece casi siempre en niveles con cierto contenido en terrígenos.

\section{Siphonodendron irregulare (Phillips, 1836)} Tabla 5; Fig. 13a

*1836 Lithodendron irregulare Phillips;. 202; lám. 2, figs. 14-15. 

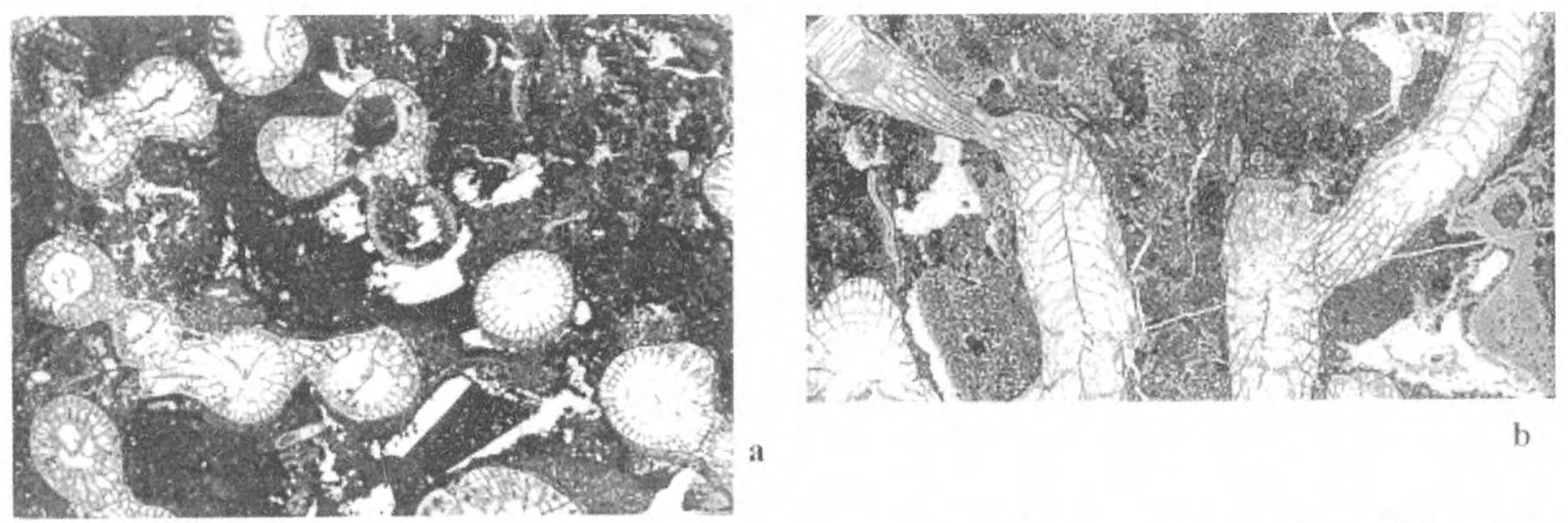

b
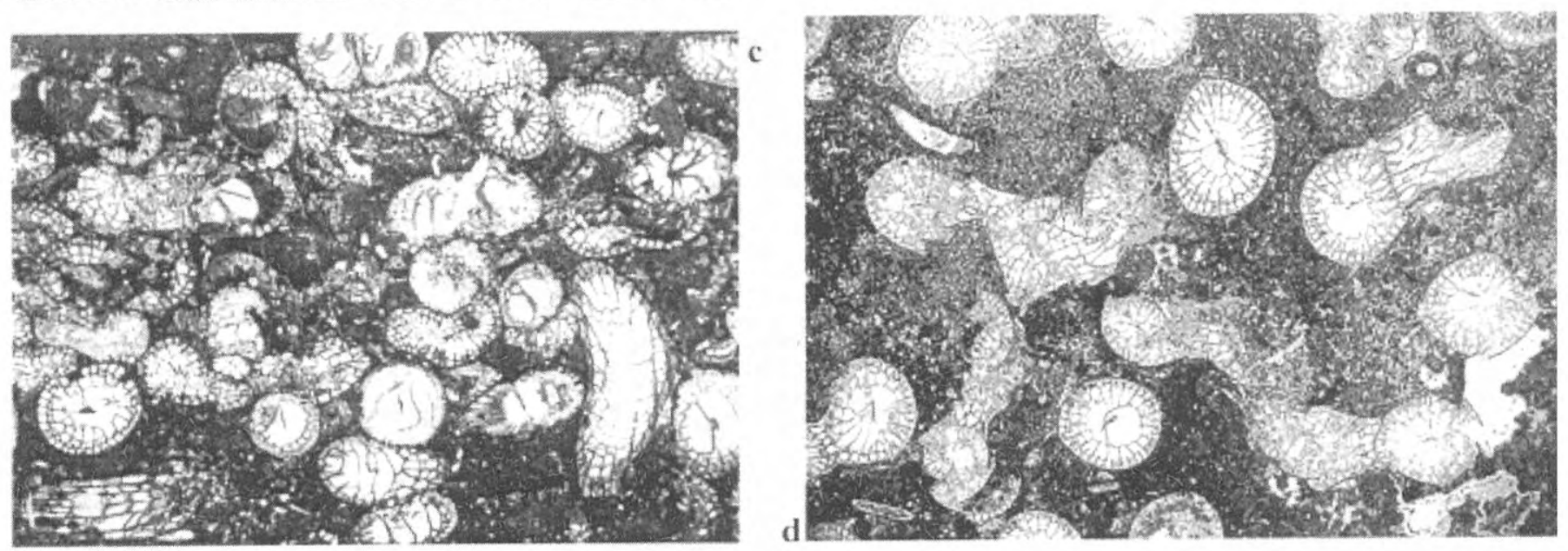

Figura 12. Siphonodendron pauciradiale (McCoy, 1844). a: SSE/18-9. Sección transversal, x3. b: SSE/18-8. Sección longitudinal, x3. c: SSE/24-1. Sección transversal de una colonia muy fragmentada, x3. d: SSE/18-8. Sección transversal, $\mathrm{x} 3$.

a: SSE/18-9. Transverse section, x3. $b$ : SSE/18-8. Longitudinal section, x3. $c$ : SSE/24-1. Transverse section of a broken colony, x3. $d$ : SSE/18-8. Transverse section, $x 3$.

1940 Lithostrotion pauciradiale (Mc Coy); Hill, partim, 169-171; lám. 9, figs. 1-2.

1981 Siphonodendron "irregulare" (Phillips); Poty, 30-31; lám. 12, figs. 1-4.

1991 Siphonodendron irregulare (Phillips); Fontaine et al., 47-48; lám. 16, figs. 1-6.

1992 Siphonodendron irregulare (Phillips); Rodríguez y Falces, 203-205; lám. 19, figs. 1-3.

Material: Tres fragmentos de colonias (COL/5-8; COL/138; COL/14-7).

Diagnosis (según Poty, 1981)

Especie de Siphonodendron dendroide o faceloide. Poliperitos con un diámetro medio de $5 \mathrm{~mm}, 21$ septos de media en cada ciclo y 26 como máximo. El disepimentario comprende típicamente una sola fila de disepimentos, aunque puede poseer hasta 4 . El crecimiento es lateral .

\section{Descripción}

Caracteres externos: Colonias fasciculadas faceloides, con poliperitos entre 4,77 y $5,33 \mathrm{~mm}$ de diámetro alar medio y entre 3,69 y 3,83 mm de diámetro tabular medio (Tabla 5).
Caracteres internos: La muralla es lisa, simple o ligeramente ondulada y puede ser fina o estar engrosada. Poseen de 1 a 3 filas de disepimentos regulares, interseptales y finos. El disepimentario mide aproximadamente 1/4 del radio alar. El número de filas de disepimentos decrece en corales con muralla engrosada. Presentan una disepiteca formada por el engrosamiento de la fila más interna del disepimentario. En sección longitudinal los disepimentos son alargados y verticales.

Los septos son, generalmente, rectos, cortos, finos y con una disposición radial a ligeramente fasciculada. La media de las colonias oscila entre 21,86 y 25,64 . Pocos septos llegan hasta la columnilla. Los septos menores son cortos, rectos y finos. Su longitud es mayor o igual al disepimentario.

La columnilla es simple, alargada o lanceolada y generalmente engrosada. Se forma por el alargamiento y engrosamiento del septo antípoda. Esporádicamente se puede unir también al septo cardinal (Fig. 13a).

\section{Microestructura}

La microestructura de la muralla es lamelar. Los septos son fibrosos, se rompen en ocasiones en fascículos de fibras; sin diferenciación de fases (water jet o jet d'eau). Los disepi- 


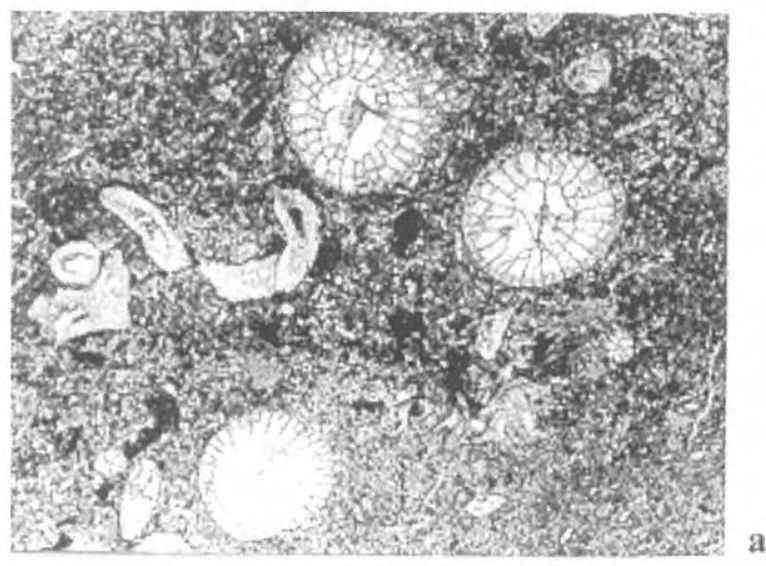

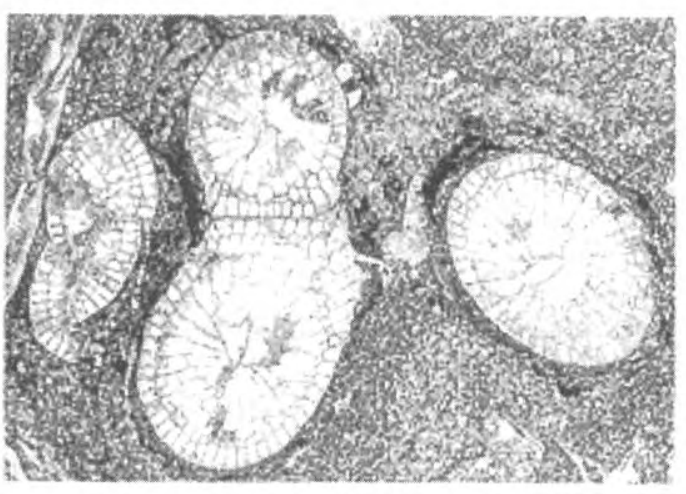

b

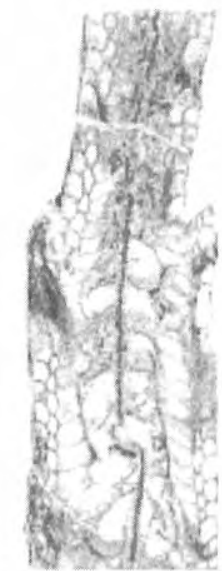

Figura 13. a. Siphonodendron irregulare (Phillips, 1836). COL/14-7. Sección transversal, x3. b-c: Siphonodendron intermedium Poty, 1981; b: CCS/8-1. Sección transvesal de un fragmento de colonia, x3; c: CCS/8-1 Sección longitudinal mostrando un rejuvenecimiento muy marcado, $\mathrm{x} 3$.

a: Siphonodendron irregulare (Phillips, 1836). COL/14-7. Transverse section, $x 3$. $\boldsymbol{b}$ - $\boldsymbol{c}$ : Siphonodendron intermedium Poty, 1981; b: CCS/8-1. Transverse section, x3; $c$ : CCS/8-1, Longitudinal section showing a conspicuous rejuvenescence, $x 3$.

mentos y tábulas son microgranulares. Los engrosamientos sobre los disepimentos, tábulas y septos son microlamelares. En las zonas gruesas el estereoplasma microlamelar se superpone al mesoplasma en fascículos de fibras.

\section{Discusión}

Después de Siphonodendron martini, esta especie es la más frecuente en Europa occidental. La descripción original indicaba que formaba con frecuencia colonias dendroides muy irregulares y no faceloides, de ahí su nombre. Sin embargo, en los ejemplares de la Cantera del Castillo y del Collado no se aprecia este carácter. Lo mismo sucede en los ejemplares de esta especie descritos en Los Santos de Maimona por Rodríguez y Falces (1992) y en los ejemplares descritos en Bélgica por Poty (1981), por lo que no parece ser ésta una característica típica de la misma.

\begin{tabular}{|c|c|c|c|c|}
\hline \multicolumn{2}{|c|}{ Siglas } & n. s. & d. t. & d. a. \\
\hline \multirow{4}{*}{ COL/5-8 } & Media & 22,4 & 3,69 & 5,31 \\
\cline { 2 - 5 } & Rango & $17-25$ & $2,15-5,23$ & $4,46-6,92$ \\
\cline { 2 - 5 } & $\mathbf{N}^{\mathbf{0}}$ datos & 17 & 17 & 17 \\
\hline \multirow{4}{*}{ COL/13-8 } & Media & 25,64 & 3,83 & 5,33 \\
\cline { 2 - 5 } & Rango & $20-29$ & $3,07-5,08$ & $4,46-6,92$ \\
\cline { 2 - 5 } & $\mathbf{N}^{\mathbf{0}}$ datos & 12 & 12 & 12 \\
\hline \multirow{4}{*}{ COL/14-7 } & Media & 21,86 & 3,75 & 4,77 \\
\cline { 2 - 5 } & Rango & $17-25$ & $2,62-5,23$ & $3,38-6,92$ \\
\cline { 2 - 5 } & $\mathbf{N}^{\mathbf{0}}$ datos & 7 & 7 & 7 \\
\hline
\end{tabular}

Tabla 5. Medidas en algunos ejemplares de Siphonodendron irregulare.

Measurements in some specimens of Siphonodendron irregulare.

\section{Siphonodendron intermedium Poty, 1981}

Tabla 6; Fig. 13b,c

*1981 Siphonodendron intermedium Poty; 29-30, lám. 10, fig. 2; lám. 11, figs. 1-3.

1994 Siphonodendron intermedium Poty y Hannay, 64, lám. 5 , fig. 5 .

Material: 4 fragmentos de colonias (COL/14-1; CCS/8-1; CCS/11-6; CCS/11-7).

\begin{tabular}{|c|c|c|c|c|}
\hline \multicolumn{2}{|c|}{ Siglas } & n. s. & d. t. & d. a. \\
\hline \multirow{4}{*}{ CCS/8-1 } & Media & 24,33 & 4,21 & 5,64 \\
\cline { 2 - 5 } & Rango & $23-25$ & $3,85-4,77$ & $5,08-6,15$ \\
\cline { 2 - 5 } & $\mathbf{N}^{\text {0 datos }}$ & 3 & 3 & 3 \\
\hline \multirow{4}{*}{ CCS/11-6 } & Media & 23,8 & 4,49 & 5,77 \\
\cline { 2 - 5 } & Rango & $23-25$ & $3,69-5,38$ & $5,08-6,62$ \\
\cline { 2 - 5 } & $\mathbf{N}^{0}$ datos & 5 & 5 & 5 \\
\hline \multirow{4}{*}{ CCS/11-7 } & Media & 24,6 & 4,65 & 5,85 \\
\cline { 2 - 5 } & Rango & $24-26$ & $3,85-5,07$ & $4,92-6,46$ \\
\cline { 2 - 5 } & $\mathbf{N}^{0}$ datos & 5 & 5 & 5 \\
\hline \multirow{4}{*}{ COL/14-1 } & Media & 23 & 4,56 & 5,08 \\
\cline { 2 - 5 } & Rango & $22-24$ & $3,85-4,77$ & $4,92-5,23$ \\
\cline { 2 - 5 } & $\mathbf{N}^{0}$ datos & 4 & 4 & 4 \\
\hline
\end{tabular}

Tabla 6. Medidas en algunos ejemplares de Siphonodendron intermedium.

Measurements in some specimens of Siphonodendron intermedium. 


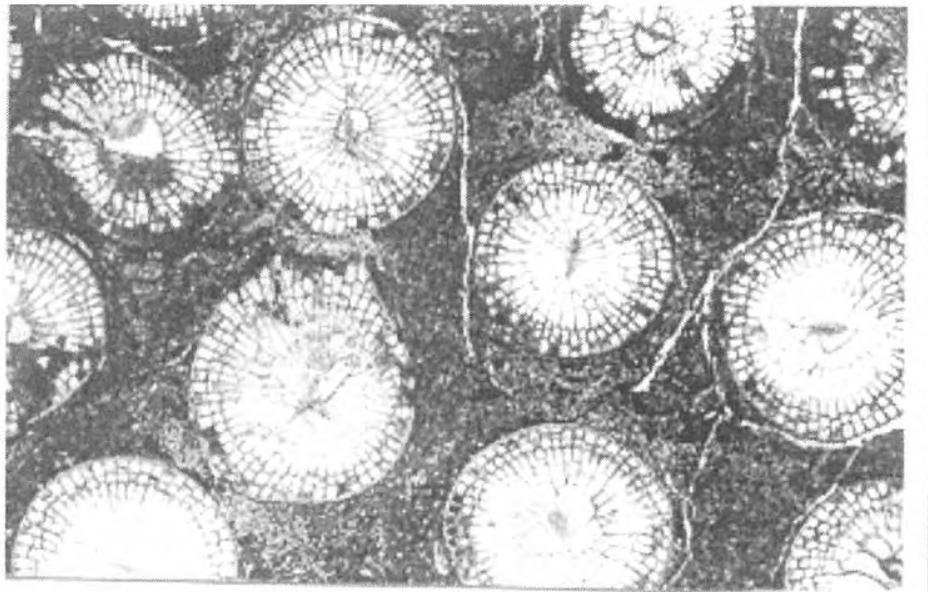

a

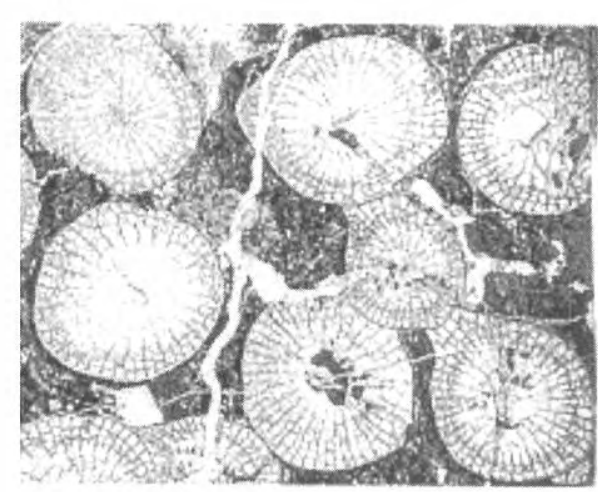

c
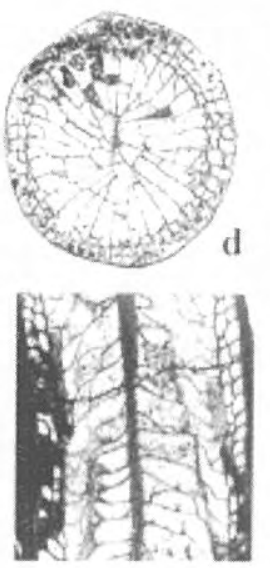

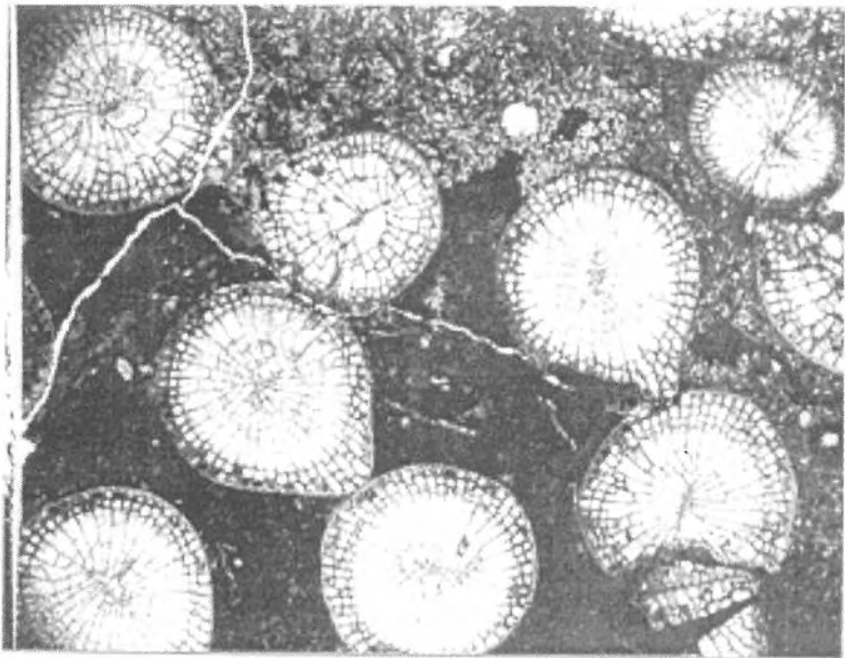

b

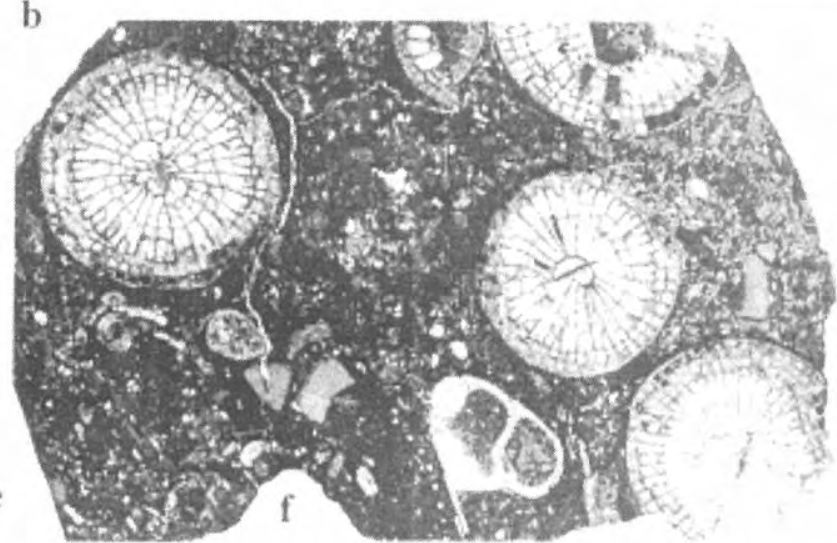

Figura 14. Siphonodendron martini (Milne-Edwards y Haime, 1851). a: COL/5-1. Sección transversal, x3. b: COL/13-24. Sección transversal, x3. c: COL/4-14. Sección transversal, x3. d: COL/1-4. Sección transversal, x3. e: COL/13-28. Sección longitudinal, x3. f: COL/2a-2. Sección transversal, x3.

a: COL/5-1. Transverse section, x3. b: COL/13-24. Transverse section, x3. c: COL/4-14. Transverse section, x3. d: COL/1-4. Transverse section, x3. e: COL/13-28. Longitudinal section, x3. $f: C O L / 2 a-2$. Transverse section, x3.

Diagnosis (según Poty, 1981)

Colonias faceloides. Poliperitos de 5,2 a $6,2 \mathrm{~mm}$ de diámetro medio, 21 a 24 septos de media y con un máximo de 26 en cada ciclo. La longitud de los septos varía en relación con el radio de las secciones. Los septos menores son cortos. El disepimentario es estrecho, comprende 2 filas de disepimentos simples. El diámetro del tabulario varía generalmente entre 4 y $5 \mathrm{~mm}$. El crecimiento es lateral.

\section{Descripción}

Caracteres externos: Fragmentos de colonias fasciculadas faceloides, con una fuerte variación de dimensiones de unos individuos a otros.

Caracteres externos: Los diámetros alares medios de los individuos en cada colonia oscilan entre 5,08 y $5,85 \mathrm{~mm}$ y los diámetros medios del tabulario están comprendidos entre 4,16 y 4,65 para las colonias estudiadas (Tabla 6).

La muralla es simple, fina y lisa. Se observa un disepimentario estrecho, cuya longitud aproximada es $1 / 5$ del radio alar y formado por 1 o 2 filas de disepimentos interseptales, regulares y finos. No hay una disepiteca muy marcada, ya que sólo se distingue en una colonia. En sección longitudinal los disepimentos son alargados o semi-globosos y verticales.

Los septos mayores son finos, rectos o con tendencia sinuosa y con disposición radial. Su media varía de 23 a 24,6 . Son medianos a largos, llegando muy pocos a unirse a la columnilla. Los septos menores son finos, rectos y cortos, pero su longitud es ligeramente superior a la anchura del disepimentario.

Las tábulas son completas o incompletas, con una inclinación mayor en la zona de la columnilla. Están muy densamente dispuestas, ya que llegan a ser más de 20 por $\mathrm{cm}$.

La columnilla es simple y está formada por engrosamiento del septo antípoda. Su morfología es laminar o lanceolada y tiene un grosor variable. En los ejemplares observados es muy persistente (Fig. 13b,c).

\section{Microestructura}

La microestructura de la muralla es lamelar. Los septos son fibrosos; las fibras se disponen en ocasiones en fascículos; no se observa diferenciación de fases. Los disepimentos y las tábulas son microgranulares. Los engrosamientos sobre los disepimentos, tábulas y septos son microlamelares. 


\begin{tabular}{|c|c|c|c|c|}
\hline \multicolumn{2}{|c|}{ Siglas } & n.s. & d. $t$. & \\
\hline & Media & 24 & 5.69 & 7.23 \\
\hline \multirow[t]{2}{*}{ CCS/10-1 } & Rango & 24 & 5.69 & 7.23 \\
\hline & $\mathrm{N}^{\circ}$ datos & 1 & 1 & 1 \\
\hline \multirow{3}{*}{$\mathrm{CCS} / 10-3$} & Media & 25 & 5.23 & 7.85 \\
\hline & Rango & $22-28$ & $4.15-6.62$ & $6.31-8.92$ \\
\hline & $\mathrm{N}^{0}$ datos & 6 & 6 & 6 \\
\hline \multirow{3}{*}{$\mathrm{CCS} / 12-9$} & Media & 24.6 & 5.54 & \\
\hline & Rango & $22-26$ & $4.92-5.85$ & $6.92-8.46$ \\
\hline & $\mathrm{N}^{\circ}$ datos & 5 & 5 & 5 \\
\hline \multirow{3}{*}{$\mathrm{CCS} / 13-4$} & Media & 27.75 & 5.88 & 6.62 \\
\hline & Rango & $27-28$ & $5.54-6.4$ & $6.31-6.92$ \\
\hline & $\mathrm{N}^{0}$ datos & 4 & 4 & 4 \\
\hline \multirow{3}{*}{$\mathrm{COL} / 1-4$} & Media & 26.2 & 5.71 & 7.74 \\
\hline & Rango & $23-28$ & $5.28-6.46$ & $6.64-9.44$ \\
\hline & $\mathrm{N}^{0}$ datos & 7 & 7 & 7 \\
\hline \multirow{3}{*}{ COL/2-4 } & Media & 26.33 & 5.58 & 7.27 \\
\hline & Range & $26-28$ & $4.92-6.61$ & $7.08-8.77$ \\
\hline & $\mathrm{N}^{\circ}$ datos & 6 & 6 & 6 \\
\hline \multirow{3}{*}{$\mathrm{COL} / 2 \mathrm{~A}-2$} & Media & 27.5 & 5.58 & 7.33 \\
\hline & Rango & $27-28$ & $5.08-6.0$ & $6.77-8.15$ \\
\hline & $\mathrm{N}^{\circ}$ datos & 4 & 4 & 4 \\
\hline \multirow{3}{*}{$\mathrm{COL} / 2 \mathrm{~A}-3$} & Media & 27.92 & 5.93 & 8.04 \\
\hline & Rango & $27-30$ & $5.07-7.54$ & $6.61-9.08$ \\
\hline & $\mathrm{N}^{0}$ datos & 13 & 13 & 13 \\
\hline \multirow{3}{*}{$\mathrm{COL} / 4-14$} & Media & 23.22 & 5.07 & 7.01 \\
\hline & Rango & $20-25$ & $3.23-6.31$ & $4.46-7.85$ \\
\hline & $\mathrm{N}^{0}$ datos & 30 & 30 & 30 \\
\hline \multirow{3}{*}{ COL/5-1 } & Media & 26.88 & 5.24 & 6.98 \\
\hline & Rango & $24-31$ & $4.0-8.0$ & $5.08-10.0$ \\
\hline & $\mathrm{N}^{0}$ datos & 42 & 42 & 42 \\
\hline \multirow{3}{*}{ COL/7-9 } & Media & 27 & 5.23 & 6.92 \\
\hline & Rango & 27 & $5.0-5.46$ & $6.80-7.04$ \\
\hline & $\mathrm{N}^{0}$ datos & 2 & 2 & 2 \\
\hline \multirow{3}{*}{ COL/13-11 } & Media & 25.56 & 5.73 & 7.54 \\
\hline & Rango & $24-27$ & $5.69-5.85$ & $7.08-8.0$ \\
\hline & $\mathrm{N}^{0}$ datos & 9 & 9 & 9 \\
\hline \multirow{3}{*}{ COL/13-24 } & Media & 28.52 & 5.22 & 6.67 \\
\hline & Rango & $25-31$ & $3.54-6.15$ & $4.46-7.69$ \\
\hline & $\mathrm{N}^{0}$ datos & 30 & 30 & 30 \\
\hline \multirow{3}{*}{ COL/13-28 } & Media & 26.05 & 4.53 & 6.09 \\
\hline & Rango & $24-28$ & $3.54-5.54$ & $4.92-7.69$ \\
\hline & $\mathrm{N}^{0}$ datos & 21 & 21 & 21 \\
\hline \multirow{2}{*}{ SSE $/ 21-9$} & Media & 24.24 & 4.86 & 6.19 \\
\hline & Rango & $\frac{23-25}{13}$ & $\frac{4.60-5.50}{13}$ & $\frac{5.7-7.0}{13}$ \\
\hline
\end{tabular}

Tabla 7. Medidas en algunos ejemplares de Siphonodendron martini.

Measurements in some specimens of Siphonodendron martini.

\section{Discusión}

Poty (1981) describe esta especie, cuya posición morfológica es intermedia entre Siphonodendron martini y Siphonodendron irregulare. El número de septos y el diámetro alar en Siphonodendron intermedium puede presentar solapamientos con los valores máximos de Siphonodendron irregulare y con los valores mínimos de S. martini; sin embargo, cuando se utiliza el diámetro del tabulario, el rango de $S$. intermedium queda claramente diferenciado de las dos especies citadas. Las características y las dimensiones de los ejemplares de la Sierra del Castillo coinciden con los ejemplares de Siphonodendron intermedium descritos en Bélgica. El número de septos está próximo al límite superior de la especie, mientras que el diámetro alar es ligeramente superior a la media de la especie.
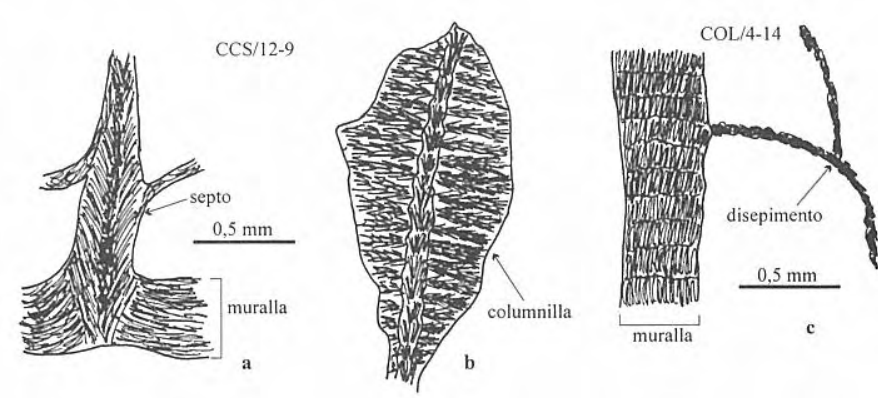

Figura 15. Microestructura de Siphonodendron martini. a: Muralla y base septal. b: Columnilla. c: Muralla y disepimentos.

a: Wall and septal base microstructure. $b$ : Column microstructure. $c$ : Wall and dissepiments microstructure.

\section{Siphonodendron martini (Milne-Edwards y Haime, 1851) \\ Tabla 7; Figs. 14, 15}

*1851 Lithostrotion martini Milne -Edwards y Haime, 436.

1851 Lithostrotion phillipsi Milne-Edwards y Haime, 439.

1979 Lithostrotion martini Milne-Edwards y Haime; Semenoff-Tian-Chansky y Nudds, 258, fig. 3; lám. 5, fig. 1-4; lám. 6, figs. 6-7.

1981 Siphonodendron martini (Milne-Edwards y Haime); Poty, 27-29; lám. 9, figs. 1-3; lám. 10, fig. 1.

1992 Siphonodendron martini (Milne-Edwards y Haime); Rodríguez y Falces, 205-206; lám. 19, figs. 4-6.

Material: Aproximadamente unas quince colonias y fragmentos de colonias (COL/1-4; COL/2-4; COL/2a-2; COL/2a-3; COL/4-14; COL/5-1; COL/7-9; COL/13-11; COL/13-24; COL/13-28; CCS/10-1; CCS/10-3; CCS/12-9; CCS/13-4, SSE/21-9).

Diagnosis (según Poty, 1981)

Coralitos con un diámetro de 6 a $10 \mathrm{~mm}$ y un número de septos que oscila normalmente entre 23 y 25 y como máximo 28. El disepimentario presenta de 2 a 4 filas regulares de disepimentos simples. Reproducción lateral.

\section{Descripción}

Caracteres externos: Colonias fasciculadas faceloides. Buena parte de los ejemplares son fragmentos de colonias concentrados en niveles de tormentas (COL/1,2, CCS/10,11,12,13). Sin embargo, algunas de las colonias recolectadas del nivel COL/13 están completas.

Caracteres internos: Las colonias estudiadas tienen un diámetro alar medio que abarca desde 6,09 a 8,04 $\mathrm{mm}$ y un diámetro tabular medio entre 4,53 y $5,93 \mathrm{~mm}$. La media del número de septos mayores oscila entre 23,22 y 27,92 (Tabla 7).

La muralla es siempre lisa, simple y fina, aunque esporádicamente puede aparecer ligeramente engrosada. En algunos poliperitos de colonias pertenecientes a la Cantera del Castillo se ha observado una muralla externa suavemente ondulada. 


\begin{tabular}{|c|c|c|c|c|}
\hline \multicolumn{2}{|c|}{ Siglas } & n. s. & d. t. & d. a. \\
\hline \multirow{4}{*}{ COL/1-2 } & Media & 33 & 6,39 & 8,08 \\
\cline { 2 - 5 } & Rango & $30-35$ & $5,54-7,23$ & $7,08-9,08$ \\
\cline { 2 - 5 } & $\mathbf{N}^{\mathbf{0}}$ datos & 2 & 3 & 3 \\
\hline \multirow{4}{*}{ COL/1-3 } & Media & 28 & 7,08 & 8,85 \\
\cline { 2 - 5 } & Rango & $24-32$ & $5,85-8,31$ & $7,69-10$ \\
\cline { 2 - 5 } & $\mathbf{N}^{\text {o datos }}$ & 2 & 2 & 2 \\
\hline \multirow{4}{*}{ COL/2B-2 } & Media & 28,84 & 6,62 & 8,80 \\
\cline { 2 - 5 } & Rango & $24-31$ & $6,15-7,23$ & $8,46-9,23$ \\
\cline { 2 - 5 } & $\mathbf{N}^{0}$ datos & 6 & 6 & 6 \\
\hline \multirow{4}{*}{ COL/5-3 } & Media & 28,33 & 6,50 & 9,08 \\
\cline { 2 - 5 } & Rango & $28-29$ & $6,28-6,82$ & $7,69-10,1$ \\
\cline { 2 - 5 } & $\mathbf{N}^{\mathbf{0}}$ datos & 3 & 3 & 3 \\
\hline \multirow{3}{*}{ SSE/10-104 } & Media & 31 & 7,2 & 11,2 \\
\cline { 2 - 5 } & Rango & 31 & $6,6-7,8$ & $9,2-13,5$ \\
\cline { 2 - 5 } & $\mathbf{N}^{\mathbf{0}}$ datos & 4 & 4 & 4 \\
\hline
\end{tabular}

Tabla 8. Medidas en algunos ejemplares de Siphonodendron sociale.

Measurements in some specimens of Siphonodendron sociale.

E1 disepimentario es estrecho, con una anchura aproximada de 1/4 del radio alar y está constituido por 1 a 4 filas de disepimentos interseptales, regulares o raramente entrecruzados y finos. En la mayoría de los poliperitos se observa una disepiteca debida al engrosamiento de la fila más interna de disepimentos. En sección longitudinal los disepimentos son alargados y muy inclinados, casi verticales.

Los septos mayores son finos, largos, rectos a sinuosos y con una disposición radial. Cerca de la columnilla presentan una tendencia a una disposición fasciculada. Los septos forman fascículos con más frecuencia si su longitud es grande, por lo que en individuos con septos muy largos esta disposición fasciculada es más evidente. Generalmente la proporción de septos que se unen a la columnilla es baja. Los septos menores son finos, rectos, cortos y con una longitud mayor o igual a la anchura del disepimentario.

En sección transversal se observan de 2 a 4 filas de tábulas finas y la sección longitudinal nos muestra que las tábulas son muy abundantes, completas o incompletas y con morfología cónica en la unión a la columnilla.

La columnilla es simple y se forma por alargamiento y engrosamiento del septo antípoda. Es laminar o lanceolada y comunmente se muestra engrosada. Rara vez se une al septo cardinal (Fig. 14).

\section{Microestructura}

La microestructura de la muralla es lamelar (Fig. 15). Los septos son fibrosos; las fibras se asocian en ocasiones en fascículos; no presentan diferenciación de fases. Los

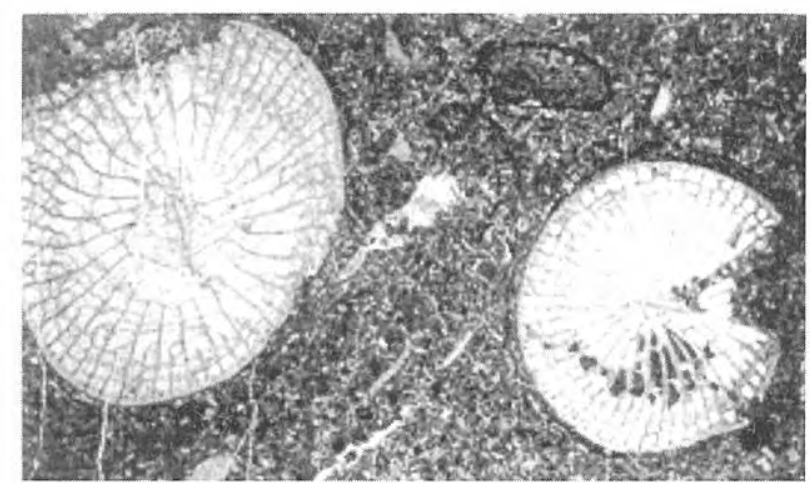

Figura 16. Siphonodendron sociale (Phillips, 1836) COL/53. Sección transversal, x3. COL/5-3. Transverse section, $x 3$.

disepimentos y tábulas son microgranulares. Los engrosamientos sobre los disepimentos, tábulas y septos son microlamelares.

\section{Discusión}

Las características de los ejemplares de Siphonodendron martini de la Sierra del Castillo encajan perfectamente con las dimensiones y caracteres de la especie en otras zonas de Europa, como Islas Británicas y Bélgica. Esta es la especie de coral rugoso más frecuente en el Viseense. Los ejemplares estudiados representan tan sólo un pequeñísimo porcentaje de los observados en el campo. Algunos niveles, como los superiores de la columna de la Cantera y los inferiores de la columna del Collado, están constituidos en su mayor parte por fragmentos de colonias de esta especie concentrados por tormentas. También son frecuentes en muchos otros niveles de la Unidad del Castillo y de otras zonas del Área del Guadiato. Esta abundancia se repite en todos los afloramientos conocidos del Viseense superior de Europa Occidental y de toda la provincia mediterránea. De hecho se puede calificar el Asbiense como la edad de Siphonodendron martini.

\section{Siphonodendron sociale (Phillips, 1836) Tabla 8; Fig. 16}

*1836 Lithodendron sociale Phillips, 203; lám. 2 fig. 19.

1851 Lithostrotion affine (Fleming); Milne-Edwards y Haime, 437.

1930 Lithostrotion sociale (Phillips); Hudson, 98, lám. 1, fig. 1

1981 Siphonodendron sociale (Phillips); Poty, 32-33, lám. 13, fig. 2; lám 14, fig. 2.

1992 Siphonodendron sociale (Phillips); Rodríguez y Falces, 206; lám. 20, figs. 1-2.

Material: 5 fragmentos de colonias (COL/1-2; COL/1-3; COL/2b-2; COL/5-3, SSE/10-104).

\section{Diagnosis (enmendada)}

Especie de Siphonodendron dendroide o faceloide. Poliperitos con un diámetro medio de 9,7 a 11,3 mm, 28 

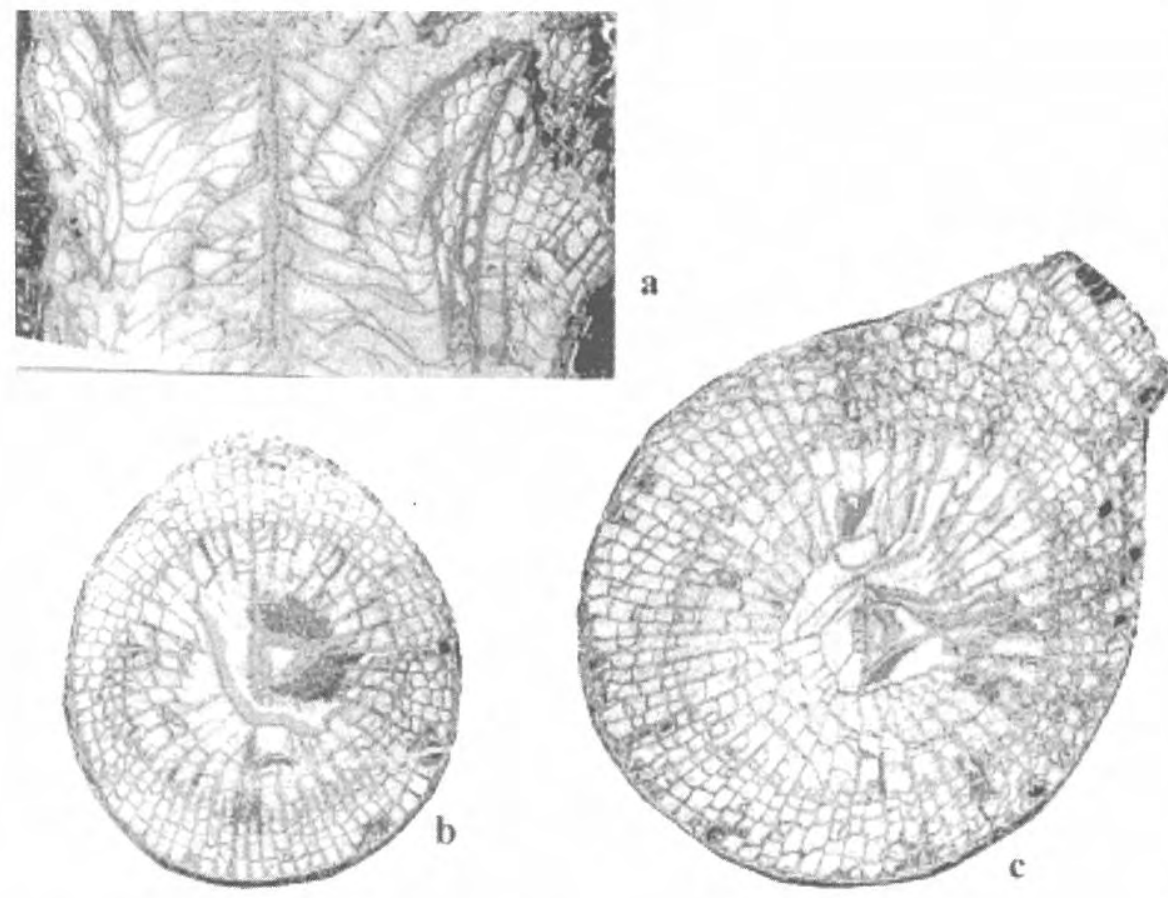

d

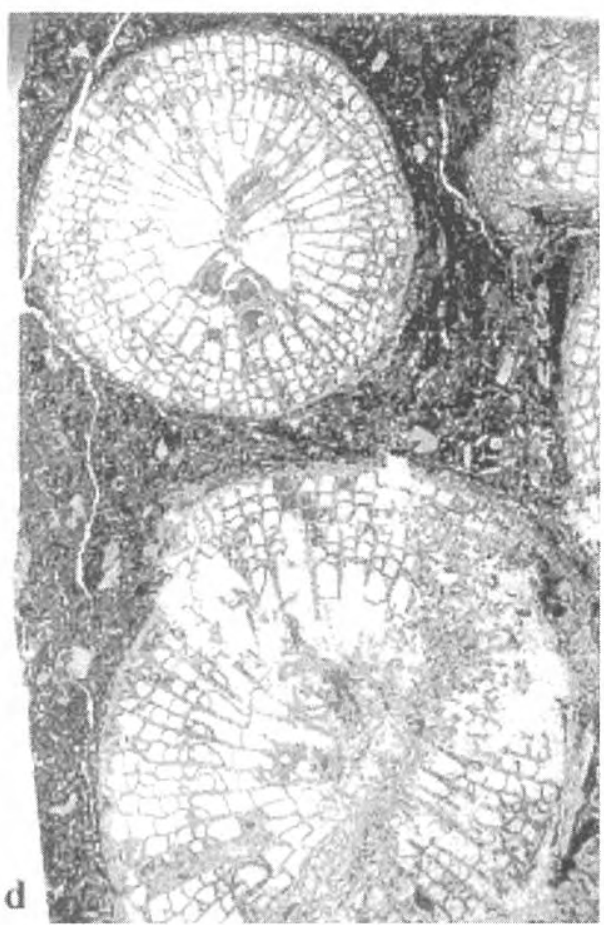

Figura 17. Siphonodendron scaleberense Nudds y Somerville, 1987. a: SSE/14-1. Sección longitudinal, x3. b: SSE/4-1. Sección transversal, x3. c: SSE/4-1. Sección transversal, x3. d: SSE/4-1. Sección transversal, x3.

a: SSE/14-1. Longitudinal section, x3. b: SSE/4-1. Transverse section, x3. c: SSE/4-1. Transverse section, x3. d: SSE/4-1. Transverse section, $x 3$.

a 31 septos de media y un máximo de 34 septos en cada ciclo. Gemación lateral.

\section{Descripción}

Caracteres externos: Fragmentos de colonias fasciculadas faceloides.

Caracteres internos: Los poliperitos tienen grandes dimensiones, oscilando los diámetros alares de los individuos entre 7,08 y $13,5 \mathrm{~mm}$, y los diámetros del tabulario entre 5,54 y 8,31 (Tabla 8).

La muralla es simple, lisa y fina o moderadamente gruesa.

El disepimentario es estrecho, varía entre 1/4 y 1/5 del radio alar. Consta de 2 a 3 filas de disepimentos interseptales, regulares y finos. Tiene una disepiteca marcada debido al engrosamiento de la fila más interna de disepimentos. En sección longitudinal, los disepimentos son alargados a semi-globosos y se disponen verticalmente.

Los septos mayores son rectos a ligeramente sinuosos cerca de la columnilla, finos o ligeramente engrosados en la zona del disepimentario y largos, llegando un pequeño número de ellos a tocar a la columnilla. La disposición es radial a fasciculada. Su número varía de 28 a 35 . Los septos menores son rectos, finos y cortos, aunque tienen una longitud mayor que la anchura del disepimentario.

En sección longitudinal, las tábulas son muy abundantes, finas, generalmente incompletas, aunque también se observan completas, y con morfología cónica en su unión con la columnilla.

La columnilla es simple, laminar o lanceolada y gruesa. Se forma por alargamiento y engrosamiento del septo antípoda (Fig. 16).

\section{Microestructura}

La microestructura de la muralla es lamelar. Los septos son fibrosos; sin diferenciación de fases. El desarrollo de estereoplasma lamelar está generalizado a todo el septo. Los disepimentos y tábulas son microgranulares. Los engrosamientos sobre disepimentos, tábulas y septos son microlamelares.

\section{Discusión}

En la diagnosis original (Phillips, 1836) y en la de Poty (1981) se señala que las colonias de esta especie son dendroides. Sin embargo, las figuraciones originales,

\begin{tabular}{|c|c|c|c|c|}
\hline \multicolumn{2}{|c|}{ Siglas } & n. s. & d. t. & d. a. \\
\hline \multirow{4}{*}{ COL/2-1 } & Media & 35 & 10,08 & 12,77 \\
\cline { 2 - 5 } & Rango & $33-37$ & $9,38-10,77$ & $10-15,54$ \\
\cline { 2 - 5 } & $\mathbf{N}^{0}$ datos & 2 & 2 & 2 \\
\hline \multirow{4}{*}{ SSE/13-3 } & Media & 36 & 8,4 & 12,1 \\
\cline { 2 - 5 } & Rango & 36 & 8,4 & 12,1 \\
\cline { 2 - 5 } & $\mathbf{N}^{0}$ datos & 1 & 1 & 1 \\
\hline \multirow{3}{*}{ SSE/14-1 } & Media & 38,66 & 11,7 & 16,7 \\
\cline { 2 - 5 } & Rango & $35-42$ & $9,8-14,4$ & $13,4-22,1$ \\
\cline { 2 - 5 } & $\mathbf{N}^{0}$ datos & 9 & 9 & 9 \\
\hline
\end{tabular}

Tabla 9. Medidas en algunos ejemplares de Siphonodendron scaleberense.

Measurements in some specimens of Siphonodendron scaleberense. 
tanto del holotipo (Phillips op. cit.) como del neotipo ilustrado por Hudson (1930) muestran corales faceloides. Todas las colonias recolectadas en Sierra Morena, tanto para este estudio como para otros anteriores en la cuenca de Los Santos de Maimona, son faceloides. Por ello hemos incluido también el tipo de crecimiento faceloide en la diagnosis de la especie.

La especie $S$. multiradiale Nudds y Somerville (1987) tiene dimensiones idénticas a las de $S$. sociale, pero el número de septos y la densidad de las estructuras es mucho mayor en la primera especie. Por ello consideramos plenamente justificada la diferenciación de la misma.

\section{Siphonodendron scaleberense Nudds y Somerville, 1987 \\ Tabla 9; Fig. 17}

*1987 Siphonodendron scaleberense Nudds y Somerville, 295-297, figs. 2 y 5.

Material: 3 ejemplares (COL/2-1, SSE/13-3, SSE/14-1).

\section{Diagnosis}

Especie de Siphonodendron de gran tamaño, con poliperitos cilíndricos de 13 a $20 \mathrm{~mm}$ de diámetro; diámetro del tabulario 10-14 mm; 2 o más filas de disepimentos; 30-41 septos en cada ciclo. Crecimiento lateral.

\section{Descripción}

Caracteres externos: Colonias de corales fasciculados con poliperitos de gran tamaño. Los ejemplares COL/2-1 y SSE/13-3 son simples fragmentos, pero el ejemplar SSE/141 corresponde a una colonia de gran tamaño, que sin embargo está aplastada e intensamente fracturada, por lo que no se han podido medir más que nueve coralitos. Las dos primeras presentan coralitos con diámetros de 12 a 13 mm de diámetro medio; sin embargo, en la última alcanzan hasta $22 \mathrm{~mm}$ de diámetro y muestran 42 septos mayores (Tabla 9).

Caracteres internos: Los ejemplares estudiados tienen una muralla simple, fina y lisa. El disepimentario es estrecho y consta de 4 a 6 filas de disepimentos interseptales regulares, finos y esporádicamente entrecruzados y angulosos. Su anchura es $1 / 3$ del radio y algo menor que la longitud de los septos menores.

Los septos mayores son finos, largos, rectos y presentan una disposición radial, aunque pueden presentar una ligera tendencia sinuosa y una disposición fasciculada. Su número es de 35. Los septos menores son cortos, finos y rectos.

La columnilla es simple y se forma por engrosamiento del septo antípoda. Su morfología es lanceolada y moderadamente gruesa. Algunos de los septos mayores se unen a ella.

Las tábulas son incompletas, con forma ligeramente cónica en conjunto, con el ápice situado en el eje, en contacto con la columnilla; existen también tabelas convexas (Fig. 17)

\section{Microestructura}

La microestructura de la muralla es lamelar. Los septos son fibrosos; con estereoplasma lamelar generalizado en todo el septo. Los disepimentos y tábulas son microgranulares. Los engrosamientos sobre disepimentos, tábulas y septos son microlamelares.

\section{Discusión}

Los ejemplares de $S$. scaleberense registrados en la Sierra del Castillo encajan totalmente con la morfología y dimensiones típicas de esta especie en las Islas Británicas, que por otra parte presenta un variabilidad muy alta.

\section{Siphonodendron aff. martini Milne-Edwards y Haime, 1851 \\ Tabla 10; Fig.18}

Material: Diez ejemplares, de los que hemos hecho doce secciones transversales y ocho longitudinales (ANT 1/1-1, ANT 1/1-2, ANT 1/1-3, ANT 1/1-20, ANT 1/1-24, ANT 1/1-51, ANT 1/1-55, ANT 2/1-63, ANT 2/4-1, ANT2/4-6).

\section{Descripción}

Caracteres externos: Corales coloniales fasciculados faceloides. Presentan gemación lateral. La mayor parte de las colonias son fragmentarias, aunque algunas alcanzan dimensiones superiores a 1 metro, tanto en diámetro como en altura. Los coralitos presentan diámetros alares medios entre 7 y $9 \mathrm{~mm}$, con 28 a 33 septos de cada orden (Tabla 10).

Caracteres internos: La muralla es moderadamente gruesa y ligeramente festoneada. El disepimentario presenta 3 a 6 filas de disepimentos interseptales regulares y entrecruzados; la disepiteca está muy marcada por el engrosamiento de la última fila de disepimentos. En corte longitudinal, los disepimentos son globosos y presentan un ángulo de inclinación de unos $45^{\circ}$ hacia el eje del coralito.

Los septos de primer y segundo orden son rectos y largos. Los de segundo orden tienen una longitud algo menor de $1 / 2$ de los de primer orden y sobrepasan la disepiteca, adentrándose un poco en el tabulario. Los de primer orden llegan a veces hasta la columnilla. Otros terminan en el tabulario, dejando alrededor de la columnilla una zona libre. La disposición es radial aunque en algunas ocasiones puede ser algo fasciculada. En el disepimentario, los septos son relativamente gruesos y ligeramente ondulados; al llegar al tabulario se engrosan notablemente para adelgazarse en su trayecto hacia el eje. El antípoda está en contacto con la columnilla, y en ocasiones también con el cardinal. La fósula cardinal está bien desarrollada.

En el tabulario se distinguen tábulas axiales y periaxiales. Hay una zona central con tábulas axiales cónicas y una zona más externa con tábulas periaxiales cóncavas y recurvadas hacia arriba en su límite con el disepimentario. Estas últimas se apoyan sobre las tábulas axiales. En corte transversal se aprecian 6 o 7 filas de tábulas concéntricas.

La estructura axial es simple y está constituida por una lamela engrosada con morfología lanceolada. En ocasiones se observan denticulaciones en la columnilla. Por lo general, 


\begin{tabular}{|c|c|c|c|c|}
\hline \multicolumn{2}{|c|}{ Siglas } & n. $s$. & d. t. & d. $a$. \\
\hline \multirow{3}{*}{ ANT 1/1-1 } & Media & 28,6 & 5,28 & 7,38 \\
\hline & Rango & $19-33$ & $4,14-5,7$ & $5,7-8$ \\
\hline & $\mathrm{N}^{\circ}$ datos & 6 & 6 & 6 \\
\hline \multirow{3}{*}{ ANT 1/1-2 } & Media & 32 & 5,81 & 7,89 \\
\hline & Rango & & $4,71-6,57$ & $6,7-8,57$ \\
\hline & $\mathbf{N}^{0}$ datos & 2 & 3 & 3 \\
\hline \multirow{3}{*}{ ANT $1 / 1-3$} & Media & 29,09 & 5,91 & 7,91 \\
\hline & Rango & $28-31$ & $4,57-7,14$ & $6,14-9-29$ \\
\hline & $\mathrm{N}^{0}$ datos & 11 & 11 & 11 \\
\hline \multirow{3}{*}{ ANT $1 / 1-20$} & Media & 29,43 & 6,75 & 8,66 \\
\hline & Rango & $26-32$ & $6-8,31$ & $7,85-9,38$ \\
\hline & $\mathrm{N}^{0}$ datos & 7 & 7 & 7 \\
\hline \multirow{3}{*}{ ANT $1 / 1-51$} & Media & 32,8 & 5,598 & 7,68 \\
\hline & Rango & $31-34$ & $4,86-6,43$ & $6,43-9,29$ \\
\hline & $\mathrm{N}^{0}$ datos & 5 & 5 & 5 \\
\hline \multirow{3}{*}{ ANT $1 / 1-55$} & Media & 30,5 & 4,78 & 7,08 \\
\hline & Rango & $28-33$ & $3,85-5,7$ & $6-8,15$ \\
\hline & $\mathrm{N}^{0}$ datos & 2 & 2 & 2 \\
\hline \multirow{3}{*}{ ANT $2 / 1-63$} & Media & 31,64 & 6,42 & 8,26 \\
\hline & Rango & $29-36$ & $5,08-7,54$ & $6,41-9,91$ \\
\hline & $\mathrm{N}^{\circ}$ datos & 11 & 14 & 14 \\
\hline \multirow{3}{*}{ ANT 2/4-1 } & Media & 30,5 & 6,46 & 8,85 \\
\hline & Rango & $28-33$ & $6-6,92$ & $8,46-9,23$ \\
\hline & $\mathbf{N}^{0}$ datos & 2 & 2 & 2 \\
\hline
\end{tabular}

Tabla 10. Medidas en algunos ejemplares de Siphonodendron aff. martini.

Measurements in some specimens of Siphonodendron aff. martini.

el septo cardinal y el antípoda están unidos a la lámina media, aunque en ocasiones sólo lo está el antípoda. En sección longitudinal se observa un eje central del que parten fibras radiales. No se aprecia orientación homogénea de las láminas medias en los distintos individuos de la colonia (Fig. 18).

\section{Microestructura}

Muralla con microestructura lamelar. Los septos son fibrosos, en chorro. En corte longitudinal se observa el contacto del septo con sus fibras dispuestas de forma fasciculada, con la muralla lamelar. Los engrosamientos estereoplasmáticos son también lamelares.

\section{Discusión}

Los ejemplares de Siphonodendron de Antolín presentan unas características especiales. El número de
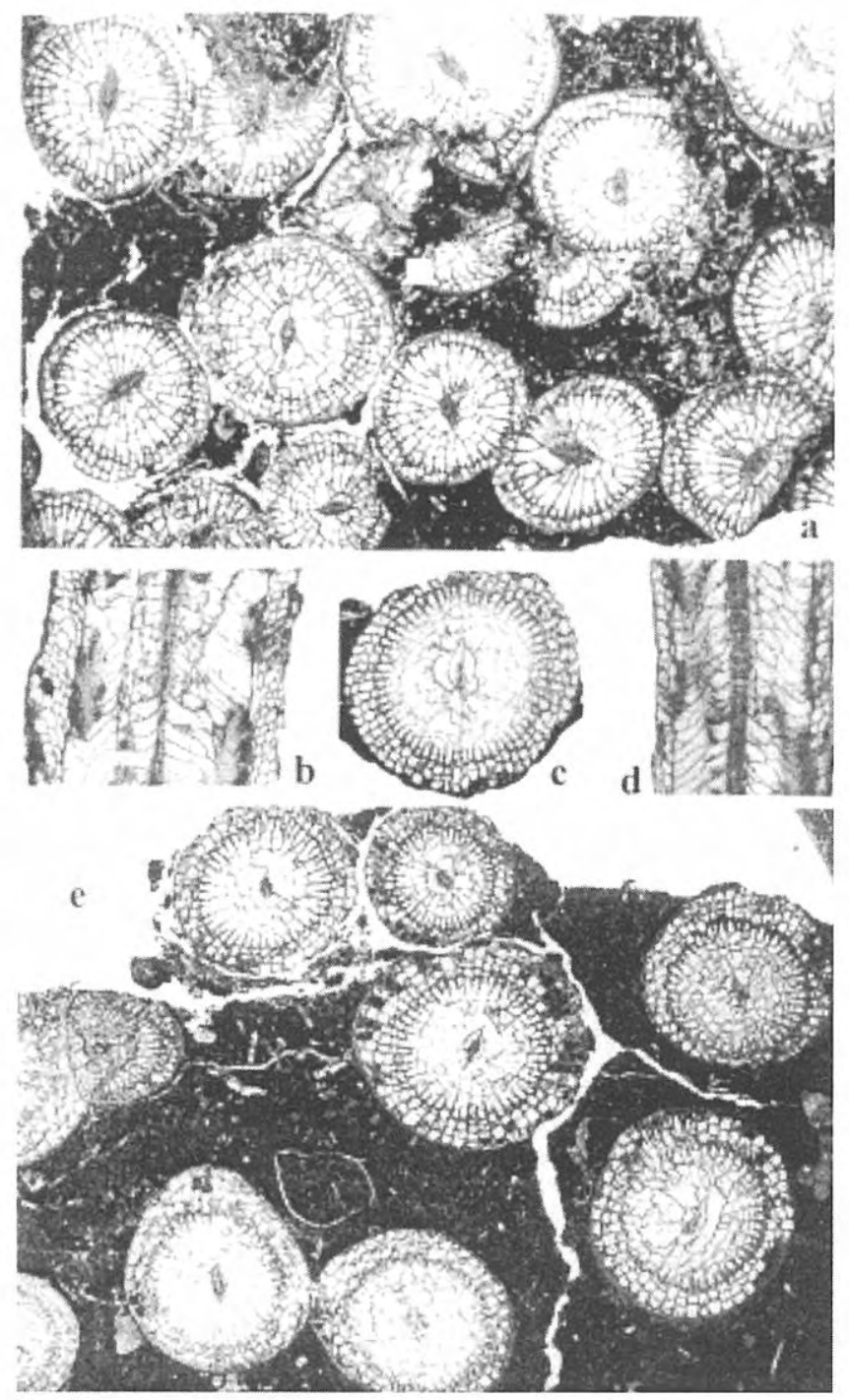

Figura 18. Siphonodendron aff. martini Milne- Edwards y Haime 1851. a: ANT 1/-20, sección transversal, x3. b: ANT/2/1-63. Sección longitudinal, x3. c: ANT 2/4-6. Sección transversal, x3. d: ANT 1/3. Sección longitudinal, x3. e: ANT 1/-24. Sección transversal. x3.

a: ANT 1/-20. Transverse section, x3. b: ANT/2/1-63. Longitudinal section x3. $c:$ ANT 2/4-6. Transverse section, x3. d: ANT 1/-3. Longitudinal section, x3. e: ANT 1/-24. Transverse section, $x 3$.

septos es muy elevado para el diámetro, según los parámetros habituales en este género. Además, todos presentan una disepiteca muy marcada y un engrosamiento generalizado de todas las estructuras. Por todo ello, no encajan con ninguna especie conocida del género. Su diámetro correspondería al de la especie $S$. martini (con la excepción del ejemplar ANT2/4-6, que es algo mayor). Sin embargo, el número de septos correspondería a la especie $S$. sociale (con la excepción del ejemplar ANT1/1-24).

Los ejemplares de Antolín presentan semejanzas con los corales descritos por Schindewolf (1928) bajo la 
denominación de S. kleffense (figurados por Weyer, 2001), que presentan estructuras ligeramente engrosadas y columnilla muy gruesa. Sin embargo, los ejemplares alemanes presentan dimensiones mayores que los de Antolín y su número de septos con relación al diámetro encaja con la definición de $S$. sociale, por lo que, en principio y a falta de mejores figuraciones, la especie alemana podría considerarse como sinónima de esta última.

Las características morfológicas relacionadas con el engrosamiento y refuerzo de las estructuras encajan con la especie $S$. multiradiale, que sin embargo es de mucho mayor tamaño. Esta última especie está adaptada a medios arrecifales (Nudds y Somerville, 1987). Los ejemplares de Antolín también se desarrollaron en medios arrecifales, por lo que podemos suponer que su especial morfología se debe a esta adaptación ecológica. Análogamente a la propuesta hecha por los autores mencionados, consideramos esta especie próxima y probablemente derivada de $S$. martini o de $S$. sociale como adaptación a medios arrecifales. Sin embargo, mantenemos de momento el material en nomenclatura abierta hasta recolectar más material y realizar estudios poblacionales más detallados.

\section{CONCLUSIONES}

Se han estudiado los lithostrotiónidos de las zonas de Antolín, Sierra del Castillo y Sierra de la Estrella en el área del Guadiato y se han identificado las siguientes especies:

Lithostrotion vorticale (Parkinson, 1808)

Lithostrotion araneum (McCoy, 1844)

Siphonodendron junceum (Fleming, 1828)

Siphonodendron pauciradiale (McCoy, 1844)

Siphonodendron irregulare (Phillips, 1836)

Siphonodendron intermedium Poty, 1981

Siphonodendron martini (Milne-Edwards y Haime, 1851)

Siphonodendron sociale (Phillips, 1836)

Siphonodendron scaleberense Nudds y Somerville, 1987

Siphonodendron aff. martini (Milne-Edwards y Haime, 1851)

Se describe por primera vez en detalle la microestructura de la mayoría de estas especies. La mayor parte de las especies de lithostrotiónidos muestran una microestructura constituida por septos fibrosos; las fibras se disponen formando fascículos, pero no llegan a formar trabéculas y tampoco se observa diferenciación de estereoplasma. Los disepimentos y tábulas son microgranulares. Los engrosamientos sobre los disepimentos, tábulas y septos son microlamelares. La microestructura de la muralla es lamelar.

La especie Siphonodendron junceum presenta una microestructura totalmente lamelar, con gránulos formando las nucleaciones iniciales en septos y tábulas. Esta tendencia a un mayor desarrollo de las lamelas se observa también en individuos juveniles de otras especies. Ello encaja con la hipótesis de que $S$. junceum evoluciona de otra especie de mayor tamaño, por un proceso de pedomorfosis (Poty, 1984), ya que desarrolla en estado adulto características juveniles de otras especies del mismo género, incluido el pequeño diámetro, la ausencia de disepimentos y la microestructura lamelar.

\section{AGRADECIMIENTOS}

Este trabajo de investigación ha sido llevado a cabo en el ámbito del proyecto de la DGICYT PB96-0842 . Varios miembros de nuestro equipo de investigación, especialmente Pedro Cózar y Elena Moreno participaron en el levantamiento de las secciones estratigráficas muestreadas; a ellos nuestro agradecimiento. Queremos agradecer también a Carlos Alonso el revelado y positivado de un buen porcentaje de las fotos de los ejemplares.

\section{BIBLIOGRAFÍA}

Cózar, P. 1994. Bioestratigrafía con foraminíferos del Carbonífero Inferior de la Sierra del Castillo (Cuenca del Guadiato, Córdoba). Tesis de licenciatura, Universidad Complutense de Madrid (inédita), 271 pp.

Cózar, P. 1996. Biozonas de foraminíferos de la Sierra del Castillo (banda central de la Cuenca del Guadiato, Córdoba). Coloquios de Paleontología, 48, 47-72.

Cózar, P. 1998. Bioestratigrafía con foraminíferos del Carbonífero Inferior del Sector Norte del área del Guadiato. Tesis doctoral de la Universidad Complutense de Madrid (inédita), 590 pp.

Cózar, P. y Rodríguez, S. 1999. Propuesta de nueva nomenclatura para las unidades del Carbonífero Inferior del Sector Norte del Área del Guadiato (Córdoba). Boletín Geológico y Minero, 110, 237-254.

Cózar, P. y Rodríguez, S. 2000. Caracterización estratigráfica y sedimentológica del Viseense Superior de Sierra Boyera (Área del Guadiato, SO de España). Revista de la Sociedad Geológica de España, 13, 91-104.

Cózar, P., Rodríguez-Martínez, M, Falces, S., Mas, R. and Rodríguez, S. (en prensa). Stratigraphical setting in the development of Upper Viséan microbial buildups of the Sierra de la Estrella (Guadiato Area, Spain). PermoCarboniferous carbonate platforms and reefs. SEPMAAPG Monography.

D'Orbigny, A. 1852. Cours élémentaire de paléontologie et de géologie stratigraphique: 2(1). Victor-Masson. Paris. $382 \mathrm{pp}$.

Falces, S. 1998. Estudio de los corales rugosos solitarios y sin disepimentos del Carbonífero de Ossa-Morena septentrional. Tesis doctoral de la Universidad Complutense de Madrid (inédita), 620 pp.

Fleming, J. 1828. A history of British animals. Beel \& Bradfute, Edimburgo, 565 pp.

Fontaine, H., Suteethorn, V. and Jongkanjanasoontorn, Y. 1991. Carboniferous corals of Thailand. CCOP Technical Bulletin, 22, 1-110. 
Hill, D. 1938-1940. A monograph on the Carboniferous rugose corals of Scotland. Palaeontographical Society Monographies, 91, 1-78; 92, 79-114; 93, 115-204.

Hill, D. 1956. Rugosa. In: Treatise on Invertebrate Paleontology (Ed. R.C. Moore). Geological Society of America \& University Kansas Press, Lawrence, F, 233324.

Hill, D. 1981. Coelenterata. Supplement 1. Rugosa and Tabulata. In: Treatise on Invertebrate Paleontology (Ed. R.C. Moore). Geological Society of America \& University Kansas Press, F, 762 pp.

Hudson, R. G. 1930. The age of the "Lithostrotion arachnoideum" fauna of the Craven Lowlands. Proceedings of the Leeds phylosphical and literary society. Scientific section, 2, 99-101.

McCoy, F. 1844. A synopsis of the characters of the Carboniferous Limestone fossils of Ireland. Dublin, 207 pp.

McCoy, F. 1849. On some new genra and species of Palaeozoic Corals and Foraminigera. Annals and magazine of Natural History, 2, 1-20.

McCoy, F. 1851. Systematic description of the British Palaeozoic fossils in the Geological Museum of the University of Cambridge. Cambridge Press, 1855, $661 \mathrm{pp.}$

Milne-Edwards, H. and Haime, J. 1850-1855. A Monograph of the British Fossil Corals. Palaeonto-graphical Society Monographies, I-LXXXV + $322 \mathrm{pp}$.

Milne-Edwards, H. et Haime, J. 1851. Monographie des Polypiers fossiles des terrains Paléozoiques, précédée d'un tableau général de la classification des Polypes. Archives du Museum d'Histoire Naturelle de París, 5, 502 pp.

Moreno-Eiris, E., Perejón, A., Rodríguez, S. and Falces, S. (Col. Cózar, P., Fernández-Martínez, E. \& FernándezRemolar, D.). 1995. Field Trid D: Palaeozoic Cnidaria and Porifera from Sierra Morena. VII Intenational Symposium on fossil Cnidaria and Porifera, Madrid, 68 pp.

Nudds, J. 1980. An illustrated key to the British lithostrotionid Corals. Acta Paleontologica Polonica, 25, 385-394.

Nudds, J. R. and Somerville, I. D. 1987. Two new species of Siphonodendron (Rugosa) from the Viséan of the British Isles. Proceedings of the Yorkshire Geological Society, 46, 293-300.

Parkinson, J. 1808. Organic remains of a former world. Volume 2. Londres, XIV + 286 pp.

Phillips, J. 1836. Illustrations of the geology of Yorkshire. Part II: the Mountain Limestone district, I-XX, 253 pp.

Poty, E. 1981. Recherches sur les Tétracoralliaires et les Hétérocoralliaires du Viséen de la Belgique. Mededelingen Rijks Geologische Dienst, 35 (1), 1-161.
Poty, E. 1984. An evolutionary pattern for the western european lithostrotionidae. Palaeontographica Americana, 54, 465-469.

Poty, E. and Hannay, D. 1994. Stratigraphy of rugose corals in the Dinantian of the Boulonnais (France). Memoires de l'Institut Géologique de l'Université de Louvain, 35, 5182.

Rodríguez, S. 1984. Corales rugosos del Carbonífero del Este de Asturias. Tesis Doctoral Universidad Complutense de Madrid, 109 (84), 1-528.

Rodríguez, S. y Falces, S. 1992. Corales rugosos. In: Analisis paleontológico y sedimentológico de la Cuenca Carbonífera de los Santos de Maimona (Badajoz) (Ed. S. Rodríguez). Coloquios de Paleontología, 44, 159-218.

Rodríguez, S. y Falces, S. 1996. Los corales rugosos del Carbonífero de Ossa-Morena: estado actual de los conocimientos. Revista Española de Paleontología, Núm. Extra., 97-102.

Rodríguez, S., Rodríguez-Curt, L. y Hernando, J.M. (en prensa). Estudio de los Aulophyllidos (Rugosa) del Viseense superior de la Unidad de la Sierra del Castillo (Córdoba). Coloquios de Paleontología, 52.

Rodríguez-Martínez, M., Moreno-González, I., Rodríguez, S. y Mas, R. 2000. Sedimentación de plataforma internaexterna con desarrollo de montículos en el Viseense del sector central de la Sierra de la Estrella (Carbonífero, Córdoba). Coloquios de Paleontología, 51, 9-33.

Schindewolf, O.H. 1928. Prinzipienfragen der biologischen Systematik. Paläontologische Zeitschrift, 9, 122-169.

Semenoff-Tian-Chansky, P. 1974. Recherches sur les Tétracoralliaires du Carbonifère du Sahara Occidental. Editions du Centre Nationale de la Recherche Scientifique, Ser. 6, Science de la Terre, 30, 1-316.

Semenoff-Tian-Chansky, P. et Nudds, J. R. 1979. Révision de quelques espèces de Lithostrotion des îles Britanniques décrites par Milne-Edwards \& Haime (Tetracoralliaries carbonifères). Bulletin du Muséum national d'Histoire naturelle de Paris, IV sér., 1 (C-3), 245-283.

Spasski, N. I., Katchanov, E. I. 1971. Novie primitivnie pannekamennougolnie Koralli Altai i Urala. Zapinski Leningradskogo Ordenov Lenina i Trudovogo Krasnogo Znamenii Gornogo Instituta, 59(2), 48-64.

Verrill, A.E. 1865. Clasification of polyps. Essex Institute Proceedings, 4, 145-149.

Vuillemin, C. 1990. Les Tétracoralliaires (Rugosa) du Carbonifère Inférieur du Massif Armoricain (France). Cahiers de Paléontologie, $\mathrm{n}^{\circ}$ 6, 1-171.

Weyer, D. 2001. Korallen Unterkarbon Deutschlands. Abhandlungen und Berichte für Naturkunde, 23, 57-92. 